OPEN ACCESS

Edited by:

Rebecca Lim,

Hudson Institute of Medical Research,

Australia

Reviewed by:

Oren Schuldiner,

Weizmann Institute of Science, Israe Robert Weissert,

University of Regensburg, Germany

${ }^{\star}$ Correspondence Vinicius T. Ribas ribasvt@ufmg.br

Received: 01 May 2017 Accepted: 24 July 2017 Published: 07 August 2017

Citation:

Ribas VT and Costa MR (2017) Gene Manipulation Strategies to Identify Molecular Regulators of Axon

Regeneration in the Central Nervous System. Front. Cell. Neurosci. 11:231. doi: $10.3389 /$ fncel.2017.00231

\section{Gene Manipulation Strategies to Identify Molecular Regulators of Axon Regeneration in the Central Nervous System}

\author{
Vinicius T. Ribas ${ }^{1 *}$ and Marcos R. Costa ${ }^{2}$ \\ 1 Laboratory of Neurobiology, Department of Morphology, Institute of Biological Sciences, Federal University of Minas Gerais, \\ Belo Horizonte, Brazil, ${ }^{2}$ Brain Institute, Federal University of Rio Grande do Norte, Natal, Brazil
}

Limited axon regeneration in the injured adult mammalian central nervous system (CNS) usually results in irreversible functional deficits. Both the presence of extrinsic inhibitory molecules at the injury site and the intrinsically low capacity of adult neurons to grow axons are responsible for the diminished capacity of regeneration in the adult CNS. Conversely, in the embryonic CNS, neurons show a high regenerative capacity, mostly due to the expression of genes that positively control axon growth and downregulation of genes that inhibit axon growth. A better understanding of the role of these key genes controlling pro-regenerative mechanisms is pivotal to develop strategies to promote robust axon regeneration following adult CNS injury. Genetic manipulation techniques have been widely used to investigate the role of specific genes or a combination of different genes in axon regrowth. This review summarizes a myriad of studies that used genetic manipulations to promote axon growth in the injured CNS. We also review the roles of some of these genes during CNS development and suggest possible approaches to identify new candidate genes. Finally, we critically address the main advantages and pitfalls of gene-manipulation techniques, and discuss new strategies to promote robust axon regeneration in the mature CNS.

Keywords: genetic manipulation, adeno-associated virus, transgenic animals, axon regeneration, central nervous system

\section{INTRODUCTION}

Damage to the adult mammalian central nervous system (CNS), including acute brain or spinal cord injury, stroke, and neurodegenerative diseases, usually lead to permanent cognitive, sensory and/or motor disabilities. Axon regeneration failure is largely responsible for these long-term deficits and poor functional recovery. The promotion of robust axon regeneration in adult mammalian CNS holds great therapeutic potential for neurological disorders and is one of the major challenges in neuroscience. Moreover, the success of cell-based therapies to treat neurological disorders relies on the capacity of new neurons to grow processes and establish new synaptic contacts.

Numerous studies have focused on the characterization of the molecular mechanisms responsible for regenerative failure. In the beginning of the twentieth century seminal studies by Santiago Ramon y Cajal showed that axon fail to regenerate in the injured mature mammalian 
CNS (Ramon y Cajal, 1928), leading to the Ramon y Cajal's statement "once the development has ended, the founts of growth and regeneration of the axons and dendrites dried up irrevocably. In the adult centers the nerve paths are something fixed, ended and immutable. Everything may die, nothing may be regenerated. It is for science of the future to change, if possible, this harsh decree." Many years later, Aguayo and his colleagues showed that after providing permissive substrates composed of peripheral nervous system (PNS) "bridges," CNS axons are able to regenerate their axons (Richardson et al., 1980; Aguayo et al., 1981; David and Aguayo, 1981). These findings suggest that the CNS environment surrounding the injured adult neuron contains inhibitory factors that block regrowth.

Based on these initial reports, several research groups attempted to identify such factors and described a variety of extracellular inhibitory molecules expressed by the adult CNS oligodendrocytes and reactive astrocytes, including Nogo, myelin-associated glycoprotein (MAG), oligodendrocyte myelin glycoprotein (OMGP), chondroitin sulfate proteoglycans (CSPGs), semaphorins, and ephrins (Schwab and Bartholdi, 1996; Case and Tessier-Lavigne, 2005; Harel and Strittmatter, 2006; Yiu and He, 2006; Fitch and Silver, 2008; Schwab and Strittmatter, 2014; Silver et al., 2015). However, counteracting or removing extracellular inhibitory molecules results in limited and incomplete axon regeneration (Zheng et al., 2003; Liu et al., 2011; Mar et al., 2014; He and Jin, 2016).

Unlike adult CNS neurons, developing mammalian neurons can regenerate their axons after injury (Kalil and Reh, 1979), and grow new ones when transplanted into the injured adult CNS (Houlé and Reier, 1988), suggesting that mature mammalian CNS neurons have an intrinsically low capacity for axon growth compared to developing CNS neurons. Moreover, these findings indicate that neurons having a high capacity of axon growth are able to overcome the inhibitory environment of injured adult CNS. The capacity of axon regrowth declines greatly as neurons in the CNS mature. For instance, embryonic retinal ganglion cells have a great ability to regenerate their axons after lesion, which is dramatically reduced after birth (Bandtlow and Löschinger, 1997; Goldberg et al., 2002). Similar to developing CNS neurons, injured adult PNS neurons also have the capacity to grow their injured axons (Huebner and Strittmatter, 2009). These findings imply that the intrinsic capacity of axon outgrowth is a key feature regulating axon regeneration. This high intrinsic capacity of axon regrowth of developing CNS and adult PNS neurons is likely due to the expression of pro-regenerative genes, which allows the regeneration of damaged axons.

In the last decade, a considerable amount of research has been focused on the identification of genes regulating the intrinsic regenerative capacity of CNS neurons. Gene manipulation techniques have been widely used to modulate the expression of these genes in order to promote axon regrowth. Here, we review various studies that used genetic manipulation to foster axon regeneration after a variety of trauma to adult mammalian CNS (Table 1). We will first introduce a few commonly used gene manipulation strategies and the two most used experimental models to study axon regeneration in the adult CNS. Then, we will discuss the main findings involving the manipulation of specific genes and, based on their developmental roles, consider the possible pro-regenerative mechanisms that are triggered upon modulation of such genes.

\section{GENE MANIPULATION TECHNIQUES IN THE CNS}

Genetic manipulation approaches are particularly advantageous for studying mechanisms controlling axon regeneration, because it is possible to target and manipulate specific intracellular signaling molecules in particular neuronal types. Manipulations using viral vector-mediated gene transfer have been widely used to investigate the role of specific genes during different events that occur after CNS injuries (Table 1). In addition, the delivery of therapeutic genes to the CNS using viral vectors is also considered a valuable tool to potentially treat a number of incurable neurological disorders (Kaplitt et al., 1994; Burger et al., 2005; Cideciyan et al., 2009). Viral vectors have many advantages compared to other techniques to manipulate intracellular molecules, including delivery of recombinant proteins, naked DNA, or pharmacological substances, because it can provide long-term gene expression and targeting of specific neurons (Kaplitt et al., 1994; Klein et al., 1998; Kügler et al., 2003). The most used viral vectors for gene transfer in CNS neurons are lentiviral and recombinant adeno-associated viral (AAV) vectors. Lentiviral vectors are enveloped retroviruses containing a positive, single-stranded RNA genome, capable of infecting both dividing and non-dividing cells and provide long-term gene expression via integration into the host cells' genome (Ponder, 2000; Segura et al., 2013). However, one important disadvantage of lentiviral vectors is the potential of integration into active gene loci, which can result in insertional mutagenesis and the formation of tumors (Li et al., 2002; Schröder et al., 2002; HaceinBey-Abina et al., 2003; Themis et al., 2005). In addition, the production of lentiviral vectors is much more complex and their large diameter $(\sim 80-100 \mathrm{~nm})$ can influence their distribution into the host tissue (Vogt and Simon, 1999; Segura et al., 2013).

In the last decades, recombinant AAV vectors have emerged as a particularly promising gene delivery method into the CNS. The AAV is a small $(\sim 25 \mathrm{~nm})$, non-enveloped virus containing a linear single-stranded DNA genome $(\sim 4.7 \mathrm{~kb}$; Berns and Giraud, 1996). AAV vectors provide long-term expression, are not associated with human diseases, have a low risk of insertional mutagenesis, low immunogenicity and have the ability to efficiently transduce a variety of neurons (Kaplitt et al., 1994; Papale et al., 2009; McCown, 2011). There are 11 naturally occurring AAV serotypes and even more variants (Wu et al., 2006), which express different capsid proteins that interact with a variety of receptors on target cells, resulting in distinct cellular tropism and different kinetics of transgene expression (Rabinowitz et al., 2002; Burger et al., 2005; Cearley and Wolfe, 2006; Vandenberghe et al., 2009). This, together with the route administration, allows the user to select the most appropriate AAV serotype to transduce the neuronal cell type of interest (Auricchio et al., 2001; Allocca et al., 2007; Lebherz et al., 2008; Hutson et al., 2012). The main drawback of AAV vectors, 
TABLE 1 | Summary of studies using genetic manipulation techniques to promote regeneration.

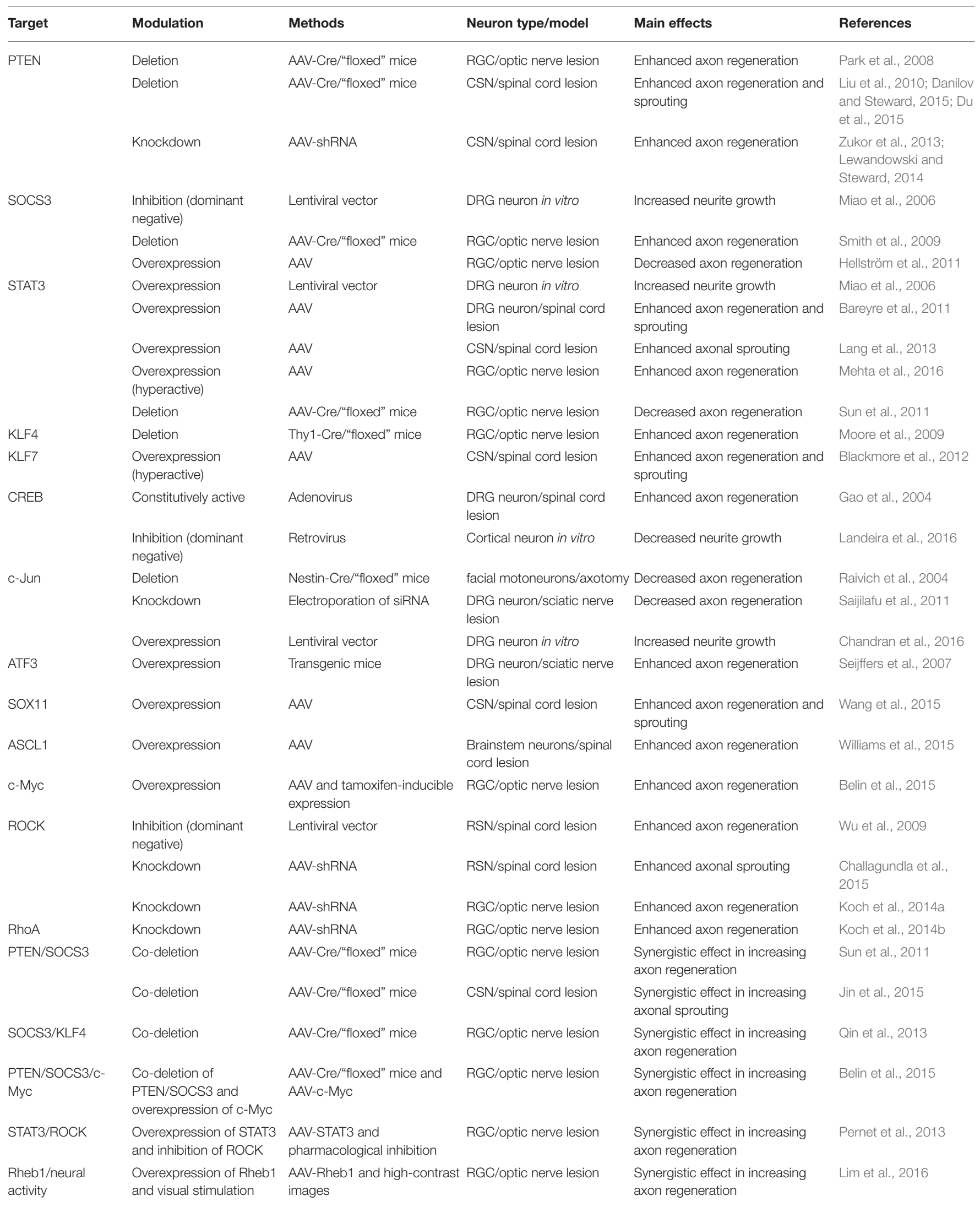

$R G C$, retinal ganglion cell; CSN, corticospinal neuron; DRG, dorsal root ganglia. 
however, is the relatively small size of the internal payload, with a maximum capacity of $\sim 4.7 \mathrm{~kb}$ (Gray et al., 2011; Hastie and Samulski, 2015). Nevertheless, recombinant AAV vectors have one of the best characterized safety profile, and have emerged as an appropriate delivery method for gene therapy into the CNS leading to an increasing number of clinical trials, including recent successes for the retinal degenerative disorder Leber's congenital amaurosis type 2 (Mandel and Burger, 2004; Cideciyan et al., 2009; Vandenberghe et al., 2009; Lim et al., 2010; Simonelli et al., 2010; Mingozzi and High, 2011; Testa et al., 2013). Therefore, AAV vectors are the method of choice to evaluate the role of specific genes and their products in axon regeneration.

Another common strategy used to manipulate gene expression in animal (specially mice) models of CNS injuries is the so-called Cre/lox system (Sauer, 1998). This is a site-specific recombination system based on the activity of the enzyme Cre recombinase (CRE), which recognizes specific 34 bp DNA sequences called loxP sites. LoxP sites are added to a transgene so that they flank a sequence of DNA, referred to as a "floxed" sequence. The enzyme CRE recognizes these loxP sites and either excise or invert DNA sequences depending on the loxP sites orientation. Transgenic mice can be engineered to express a transgene under the control of CRE. For that, a floxed stop codon is placed directly upstream of the transgene, preventing its expression. Following CRE expression, the stop codon is removed and the transgene can be expressed. Transgenic mice can also be engineered to insert loxP sites into specific endogenous genes. In these animals, CRE activity leads to the excision/inversion of DNA sequences with the consequent loss of the targeted genes. Thus, the Cre/lox system can be used to either induce or inhibit gene expression.

Tissue specific recombination can be achieved through the use of transgenic lines in which CRE expression is regulated by cell-type specific promoters. Moreover, transgenic animals carrying the gene for an enzyme CRE fused to the truncated estrogen receptor (ERT) allows the temporal control of CREmediated DNA recombination, since the nuclear transport of the fused CreERT requires the treatment with the estrogen analog Tamoxifen. For example, crossing transgenic mice expressing CreERT in neurons (Young et al., 2008) to transgenic mice carrying a "floxed" sequence in the pten gene (Park et al., 2008) would allow the temporal deletion of this gene at different timepoints after axonal injury. This strategy of gene deletion is called "conditional knockout."

Alternatively, CRE expression can be temporally and spatially controlled through the use of viral vectors carrying plasmids encoding for CRE under the control of cell-specific promoters. Most of the studies using AAV vectors to express CRE, in models of CNS injury, used ubiquitous promoters, such as cytomegalovirus (CMV; Park et al., 2008; Du et al., 2015; Geoffroy et al., 2015) and the hybrid CMV/chicken ß-actin (CAG) promoters (Bei et al., 2016), or neuronal specific promoters such as human synapsin (hSyn) (Qin et al., 2013). In addition to CRE, expression of therapeutic genes delivered by viral vectors can also be regulated through the use of cell-specific promoters.

The use of ubiquitous promoters has important caveats due to transgene expression in undesired cell types, such as local inhibitory neurons and glial cells (Nathanson et al., 2009; Watakabe et al., 2015, 2017). Moreover, it has been shown that high levels of transgene expression, driven by CMV promoter, may be toxic to neurons (Watakabe et al., 2015). The use of neuronal-specific promoters, such as hSyn, mousecalcium/calmodulin-dependent protein kinase II (CAMKII), platelet-derived growth factor- $\beta$ chain (PDGF- $\beta$ ), neuronspecific enolase (NSE), among others, can avoid expression of transgene in non-neuronal cells and also the toxic effect produced by high levels of transgene expression (Klein et al., 1998; Paterna et al., 2000; Kügler et al., 2003; Nathanson et al., 2009; McLean et al., 2014; Watakabe et al., 2015). Nonetheless, hSyn promoter controlled gene expression in the CNS leads to transgene expression in both inhibitory and excitatory neurons, whereas CAMKII promoter tend to be more specific to excitatory neurons (Watakabe et al., 2015). Similar to neurons, glial cells can also be targeted by using promoters of glia-specific genes, such as myelin basic protein $(M b p)$ for oligodendrocytes or glial fibrillary acidic protein (Gfap) for astrocytes (Lawlor et al., 2009; von Jonquieres et al., 2013). Thus, through the choice of different promoters, transgene expression can be selectively induced in distinct cell types in the CNS, which allows the evaluation of the contribution of different genes in specific cell types to axon regeneration.

\section{EXPERIMENTAL CNS INJURY MODELS}

Many different injury models are used to study axon regeneration in the CNS. Nonetheless, optic nerve lesion and spinal cord injury are the most widely used experimental strategies and will be the focus of this review. The optic nerve is part of the CNS and contains the axons of retinal ganglion cells (RGCs), the sole output of the retina. The axons of the optic nerve project to different brain areas, including the dorsal lateral geniculate nucleus, superior colliculus, and suprachiasmatic nucleus, among others. Like other areas of the CNS, optic nerve axons cannot regenerate after injury. Therefore, conditions such as glaucoma, that involves degeneration of these axons, leads to irreversible vision impairment. The optic nerve lesion model has many advantages, such as the simple anatomy (i.e., all lesioned axons belong to only one cell type), easy accessibility and the functional relevance. Moreover, gene manipulation in retinal cells, including RGCs, using viral vectors, has numerous benefits. First, the anatomical organization of the retina in which the cells are organized in different layers facilitate the transduction of specific neuronal cell types (i.e., for RGC transduction intravitreal injection is performed, while for photoreceptor transduction subretinal injection is more appropriated). Second, the structure and accessibility of the retina allow easy access to local administration of viral vectors. Finally, the eye is a compartmentalized structure and, due to the presence of the blood-retinal barrier, prevents the unintentional systemic spread of vectors, thus limiting immune responses toward the transgene and the vector proteins (Bennett, 2003; Streilein, 2003). Due to these advantages, AAV-mediated gene therapy is a common strategy employed in animal models to treat retinal diseases (Liang et al., 2001; Dejneka et al., 
2004; Acland et al., 2005; Mingozzi and High, 2011), indicating that gene manipulation using these vectors to promote axon regeneration could be a valuable strategy for clinical applications. Therefore, the optic nerve lesion model has been widely used to investigate the role of specific genes in axon regeneration in the CNS.

Spinal cord injury is another widely model to study axon regeneration in the CNS. Traumatic spinal cord injuries in humans can often result in permanent sensory and/or motor deficits (Yip and Malaspina, 2012), that cannot be sufficiently repaired by any existing therapy. One of the major challenges to achieve functional recovery after such injuries is to promote robust axonal regeneration. Usually, in animal models of spinal cord injury, the main focus is pyramidal corticospinal neurons (CSNs). CSNs are localized in the layer $\mathrm{V}$ of the primary motor cortex and send their axons directly to the spinal cord, where the majority of the axons form the dorsal corticospinal tract (CST), which in rodents runs in the ventral portion of the dorsal funiculus. The CST is an important descending motor pathway that contains the axons of neurons controlling locomotion, posture, and voluntary skilled movements, especially in the distal part of the limbs (Steward et al., 2004; Lemon and Griffiths, 2005). Damage to CST axons usually occurs after spinal cord lesion and lead to permanent motor deficits. Notably, CSNs have a particularly low capacity for axon regrowth, with minimal regeneration even after permissive tissue grafts or neutralization of extracellular inhibitory molecules (Richardson et al., 1980; Hollis et al., 2009; Lee et al., 2010). Thus, the promotion of CST regeneration remains a fundamental step to restore motor function after this type of injury.

Gene manipulation in CSNs is a common strategy to evaluate the role of genes in CST axon regeneration. To this end, most studies use AAV vectors, which are injected into the sensorimotor cortex to transduce CSNs and modulate gene expression in this neuronal type. In addition to CST axons, the spinal cord injury model is also used to evaluate axon regeneration of other axonal tracts, such as rubrospinal tract in the dorsal part of the lateral column, which is also involved in motor control, and ascending sensory axons in the dorsal column that mediate sensorial stimuli. Although, gene manipulation of these other pathways could be used to study axon regeneration in spinal cord injury models, most of the studies focused on the CST. One important disadvantage of spinal cord injury models is that usually the animals require extensive post-operative care, including deliver of fluids, pain medications, and bladder emptying to avoid urinary tract infections.

\section{PTEN/mTOR}

To date, an increasing number of studies have targeted neuron-intrinsic molecules and signaling pathways in order to increase the capacity of injured adult mammalian CNS neurons to regenerate their axons (Table 1). PTEN/mTOR pathway manipulation has resulted in one of the most robust effect on axon regeneration (Figure 1). PTEN (phosphatase and tensin homolog) is a phosphatase that inhibits protein kinase $\mathrm{B}$ ( $\mathrm{PKB}$, also termed Akt) activity through conversion of phosphatidylinositol $(3,4,5)$ trisphosphate (PIP3) to phosphatidylinositol $(4,5)$ bisphosphate (PIP2) (Guertin and Sabatini, 2007; Carnero, 2010). On the contrary, phosphoinositide 3-kinase (PI3-K) converts PIP2 to PIP3 and activates Akt, which activates the mechanistic target of rapamycin (mTOR) (Luo et al., 2003). Thus, inactivation of PTEN induces Akt activity culminating in the activation of mTOR, which is a central regulator of cellular protein synthesis, autophagy, growth and survival (Chong et al., 2012; Saxton and Sabatini, 2017). Activation of mTOR promotes protein synthesis mainly by phosphorylating the kinase $\mathrm{S} 6 \mathrm{~K}$ and the translation regulator 4E-BP1 (Ma and Blenis, 2009). In addition to promoting protein synthesis, mTOR also inhibits catabolism by blocking autophagy through the phosphorylation of the ULK1-Atg13-FIP200 complex (Jung et al., 2009). Therefore, mTOR is an important regulator of anabolism and catabolism mechanisms that could play an important role on axon regeneration.

In the developing brain, PTEN/mTOR pathway play an important role on the control of stem cell/progenitor proliferation (Groszer et al., 2001; Lehtinen et al., 2011), neuronal differentiation, migration, and process growth (Kwon et al., 2006; Hsia et al., 2014; Morgan-Smith et al., 2014). More importantly to our discussion, downregulation of PTEN in developing neurons leads to increased axonal branching and growth (Drinjakovic et al., 2010). Similarly, PTEN inhibition enhances neurite outgrowth in neurons derived from human embryonic stem cells (Wyatt et al., 2014). These observations suggest that regulation of PTEN/mTOR signaling is key to control axonal growth during development and, therefore, could be a potential target to foster regeneration in the injured adult CNS.

According to this notion, a leading study showing the effects of PTEN deletion on axon regeneration was published in 2008 (Park et al., 2008). In this study they used conditional knockout mice in which the gene encoding PTEN protein was flanked by loxP sites. They deleted PTEN in RGCs by intravitreal injection of AAV2 particles expressing Cre recombinase (AAV-Cre) in adult mice. PTEN deletion resulted in robust axon regeneration after optic nerve lesion, with a large number of regenerating axons elongating up to $4 \mathrm{~mm}$ distal to the lesion site. In addition to axon regeneration, PTEN deletion also increased RGC survival after optic nerve lesion, with a protection rate of about two-fold compared to control. Both, axon regeneration and RGC survival were reduced by application of rapamycin, an inhibitor of mTOR, suggesting that the observed effects induced by PTEN deletion are dependent on mTOR pathway (Park et al., 2008).

After these pioneer findings, several studies examined the effects of PTEN deletion in different models of CNS injury. In a follow up study from the same research team, the effect of PTEN deletion on axon regeneration was also investigated in models of spinal cord injury. Using the same approach, PTEN was deleted by injecting AAV-Cre into the sensorimotor cortex of neonatal mice in order to evaluate CSNs axon regeneration. As observed in RGCs, PTEN deletion induced robust axon regeneration after spinal cord injury, both, by enhanced compensatory sprouting of uninjured CSN axons and 


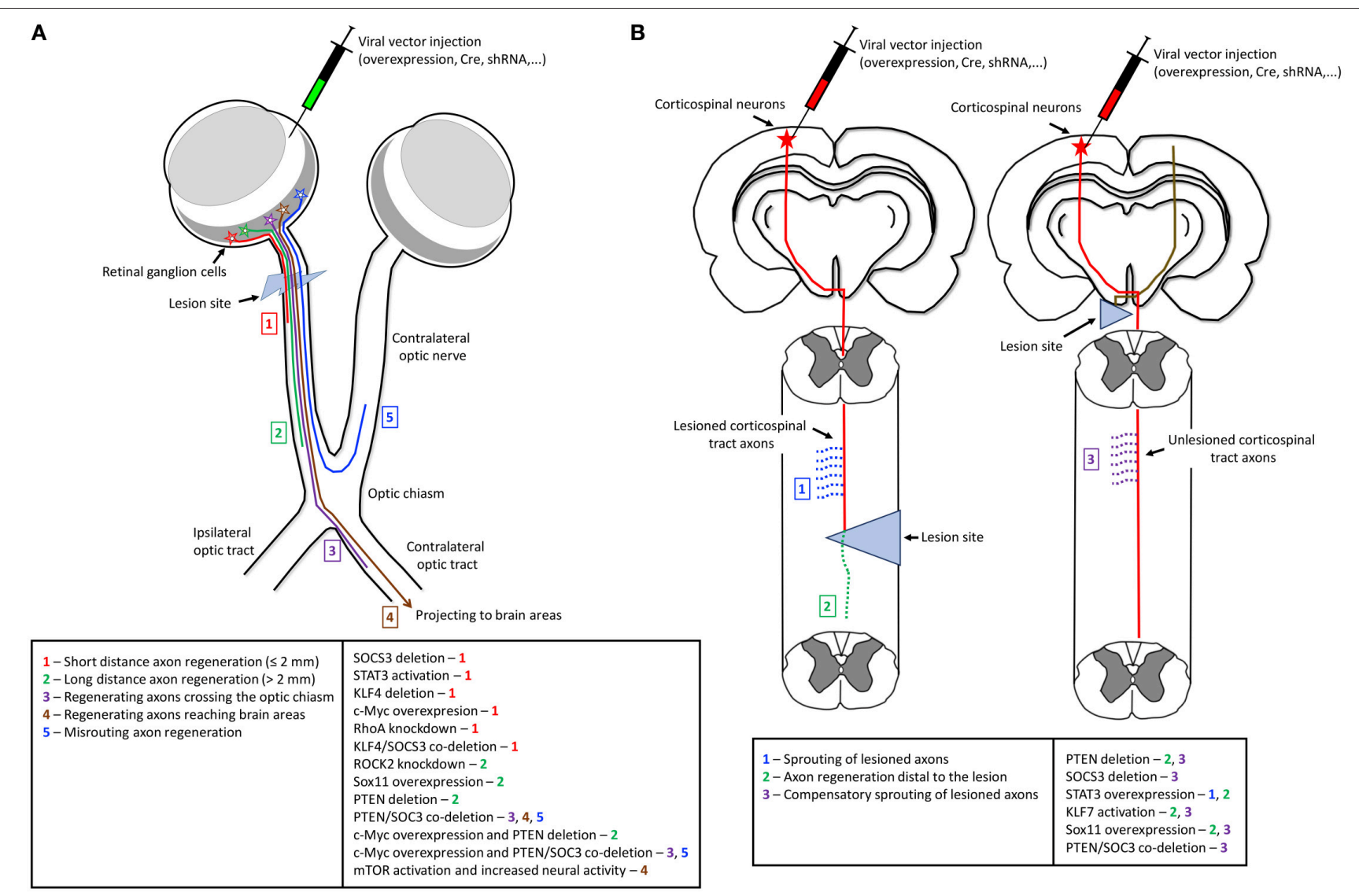

FIGURE 1 | The effects of gene manipulation on axon regeneration in optic nerve and spinal cord lesion models of CNS injury. The main technique to manipulate gene expression is by direct injections of viral vectors to overexpress specific genes, deliver Cre recombinase for gene deletion, or deliver shRNA against endogenous targets for gene knockdown. (A) In the optic nerve lesion model genetic manipulation is usually by intravitreal injections. The effects of different genes manipulation (right box) range from short distance axon regeneration up to complete axon regrowth to target areas (numbers - left box). (B) In spinal cord injury model, genetic manipulation is usually by injections into the sensorimotor cortex to transduce corticospinal neurons. The effects of manipulation of specific genes (right box) varies from sprouting of lesioned axons (1), axon regeneration distal to the lesion (2), and compensatory sprouting of unlesioned axons (3) (left box). The left scheme shows gene manipulation in lesioned neurons of a spinal cord injury model. The right scheme depicts a unilateral pyramidotomy and gene manipulation performed in unlesioned neurons.

successful regeneration of injured CSN axons distal to the lesion site (Liu et al., 2010). On both studies, the authors observed a reduction of mTOR activity in adult CNS neurons as compared to the developing CNS, and axonal lesion further reduced this activity (Park et al., 2008; Liu et al., 2010). This suggests that mTOR is a possible intrinsic regulator of axon growth which could be developmentally downregulated. Regarding the molecular mechanisms downstream of mTOR which could regulate axon regeneration, it is believed that enhancement of protein synthesis induced by mTOR activity could provide building blocks for axonal regrowth and would be the main reason for the increased axon regeneration. However, whether other downstream targets of mTOR, including autophagy, are also involved in the regulation of axon regeneration following PTEN deletion remains to be determined.

In addition to these two publications, other studies also showed that PTEN is in fact a valuable target to promote axon regeneration. Two independent studies using AAVs to deliver short hairpin RNAs (shRNA) against PTEN to CSNs, have also shown that PTEN downregulation enhances CST axon regeneration and improves the recovery of skilled motor functions after spinal cord injury in rodents (Zukor et al., 2013; Lewandowski and Steward, 2014). Moreover, conditional deletion of PTEN in CSNs enhances regrowth of CST axons and motor function recovery even after the spinal cord injury (Danilov and Steward, 2015). Notably, PTEN deletion one year after spinal cord injury still triggers robust CST regeneration (Du et al., 2015).

Although, these studies do not describe any major detectable pathology, long-term effect of PTEN interference is a potential concern, because PTEN is a tumor suppressor, whose manipulation could lead to undesirable side effects. Moreover, PTEN deletion in hippocampal dentate granule cells leads to mTOR hyper activation and promotes the rapid onset of spontaneous seizures (LaSarge et al., 2015). In a recent study, Gutilla and colleagues evaluate the long-term effect of neonatal 
PTEN deletion in mice. Albeit the authors found no evidence of tumor formation or other major neuropathology, cortical thickness was significantly increased and cortical lamination was disrupted in the area of PTEN deletion (Gutilla et al., 2016). However, the authors did not investigate the long-term effect of PTEN deletion in adult animals. Therefore, PTEN interference could be a potential pro-regenerative strategy for treating CNS injuries, but systematic studies are necessary to prove the long-term safety of PTEN interference.

\section{JAK/STAT3/SOCS3}

Several studies using gene manipulation techniques have indicated that the JAK/STAT3/SOCS3 pathway is also an important modulator of axon regeneration (Table 1; Figure 1; Liu et al., 2015). In this pathway, cytokines, including interleukin6 (IL6) and ciliary neurotrophic factor (CNTF), bind to receptors and activate the Janus kinase (JAK)/signal transducer and activator of transcription (STAT) pathway (Krebs and Hilton, 2001), a critical intracellular cascade for the transduction of extracellular signals to the nucleus. Upon binding of the ligand to its receptor, JAK phosphorylates STATs, including STAT3, which dimerizes and translocate to the nucleus, where it interacts with various regulatory elements that induce target gene expression (Darnell et al., 1994). The above signaling cascades transcriptionally regulates a family of proteins called Suppressor of cytokine signaling (SOCS), including SOCS3, which act as a negative feedback signal by inhibiting JAK and STAT activation and phosphorylation, limiting the response to cytokine and growth factors signaling (Krebs and Hilton, 2001).

One of the first evidence showing that the JAK/STAT3/SOCS3 pathway regulates axon regeneration was observed in rat primary sensory neurons in vitro (Miao et al., 2006). In this study, they showed that overexpression and activation of STAT3, by lentiviral transduction, stimulates neurite growth of cultured sensory neurons. Overexpression of SOCS3 blocks nuclear translocation of STAT3 and neurite outgrowth, and inhibition of endogenous SOCS3 through overexpression of a dominant negative mutant SOCS3 stimulates neurite outgrowth (Miao et al., 2006). Thereafter, Smith and colleagues showed, using the in vivo AAV-mediated conditional knockout approach discussed above, that deletion of SOCS3 in adult RGCs is able to promote extensive axon regrowth after optic nerve lesion. This effect was abolished by co-deletion of gp130, a shared receptor component required for this signaling, indicating that the regenerating effect of SOCS3 deletion is dependent on gp130. Moreover, injection of CNTF in SOCS3 deleted mice further increase the extent of axon regeneration (Smith et al., 2009). Consistent with these findings, overexpression of SOCS3 in RGCs, by using AAV vectors, inhibited regeneration of optic nerve axons induced by CNTF injection or peripheral nerve grafting (Hellström et al., 2011). Altogether, these studies point to SOCS3 as a pivotal negative regulator of JAK/STAT3/SOCS3 pathway in regulating axon regeneration.

Several studies suggest that STAT3 is the primary effector of axon regeneration induced by this pathway. In a study combining in vivo time-lapse fluorescence microscopy with genetic manipulations in mice, the authors showed that selective deletion of STAT3 in dorsal root ganglion (DRG) neurons impairs regeneration of peripheral DRG branches after nerve cut. In addition, overexpression of STAT3 increases outgrowth and collateral sprouting of central DRG branches after a dorsal column lesion (Bareyre et al., 2011). Thereafter, another study from the same group demonstrated that overexpression of STAT3 in CSNs enhances remodeling of lesioned CST axons and induces axonal sprouting from unlesioned CST axons, leading to functional recovery (Lang et al., 2013). More recently, Mehta and colleagues have shown that overexpression of STAT3 fused with a viral activation domain (VP16), which hyper activates the transcription activity of STAT3, in RGC results in regeneration of optic nerve axons after injury (Mehta et al., 2016). Finally, AAVmediated conditional knockout study demonstrated that SOCS3 deletion leads to significant axon regeneration in the optic nerve, while double SOCS3/STAT3 deletion reverts the regenerative effects of SOCS3 deletion alone (Sun et al., 2011). These data indicate that STAT3 is the critical mediator of axon regeneration induced by SOCS3 deletion.

Interestingly, the JAK/STAT pathway also regulates the generation of astroglial cells in the developing CNS (Bonni et al., 1997; Miller and Gauthier, 2007). Timewise, axon growth and astrogliogenesis partly overlap in the developing CNS, suggesting that these two processes are intermingled and could be manipulated to further stimulate axon growth in the injured adult CNS. According to this notion, RNA-interference (RNAi) of GFAP and Vimentin expression leads to suppression of astroglial reactivity and scarring, and increase survival and neurite growth of cortical neurons in culture (Desclaux et al., 2009).

The JAK/STAT3/SOCS3 pathway, thus, appears to play a pivotal role in controlling axon growth, and represents a promising target for therapeutic intervention. Modulating this pathway after CNS injury could help axon regeneration and ultimately functional recovery. Similar to PTEN, however, SOCS3 acts a tumor suppressor, an effect likely mediated via the JAK/STAT pathway (He et al., 2003; Tokita et al., 2007). Therefore, additional studies are necessary to confirm that manipulation of this pathway can promote long-term regenerative benefits without leading to undesired side-effects in the injured CNS.

\section{KLF FAMILY OF TRANSCRIPTION FACTORS}

The members of the Krüppel-like factors (KLF) family of transcription factors have also been implicated in the control of axon regeneration (Table 1; Figure 1). Members of this family are involved in the loss of axon growth capacity observed in RGCs around birth (Goldberg et al., 2002; Moore et al., 2009). Indeed, KLF4 expression is upregulated in RGC after birth, and overexpression of this transcription factor in embryonic RGCs induces a potent reduction in neurite outgrowth in vitro, suggesting that this protein inhibits axon elongation in these cells. Accordingly, KLF4 knockout increases the number and 
length of regenerating RGC axons after optic nerve injury (Moore et al., 2009). In addition to KLF4, overexpression of other members of the KLF family, including KLF15, KLF9, KLF14, KLF13, KLF5, KLF12, and KLF1, also decreases neurite growth in cortical neurons in vitro. Similar to KLF4, KLF9 is clearly upregulated postnatally in RGCs (Moore et al., 2009). Moreover, overexpression of another member, KLF16, inhibits RGC neurite outgrowth in vitro and enhances RGC growth cone collapse in response to exogenous ephrinA5 ligands (Wang et al., 2016). In contrast, overexpression of KLF6 and KLF7 increases neurite growth in cultured postnatal RGCs (Moore et al., 2009). Similarly, overexpression of a chimeric KLF7 with the VP16 transactivation domain in CSNs, promotes both sprouting and regenerative axon growth in the CST of adult mice (Blackmore et al., 2012). These studies point to a complex role for the KLF family of transcription factors as regulators of axon regeneration in the CNS, by both promoting and inhibiting axon growth. Thus, manipulation of different members of this family can be potentially used to promote axon regrowth after CNS injury. Although, it is clear that this family of transcription factors is involved in the control of axon regeneration, the effects of KLF manipulations are relatively modest. In addition, little is known about protein-protein interactions of the members of this family that are relevant to axon elongation in the CNS. Understanding the crosstalk between these transcription factors may yield better strategies for promoting robust CNS axon regeneration.

\section{OTHER TRANSCRIPTION FACTORS (CREB/C-Jun/ATF3/SOX11/ASCL1/c-Myc)}

The transcription factors cAMP Responsive Element Binding Protein (CREB), Jun Proto-Oncogene (c-Jun), Activating Transcription Factor 3 (ATF3), SRY (Sex Determining Region Y)-Box 11 (SOX11), Achaete-Scute Family BHLH Transcription Factor 1 (ASCL1), and the Proto-oncogene c-Myc, can also play a role on axon regeneration (Table 1; Figure 1).

The transcription factor CREB belongs to the family of leucine zipper transcription factors, which binds to the cAMP response element (CRE), a conserved DNA sequence in promoter elements that are activated by cAMP (Montminy and Bilezikjian, 1987). Overexpression of a dominant negative form of CREB in cerebellar and DRG neurons, blocks neurite growth induced by cAMP (Gao et al., 2004). Conversely, overexpression of a constitutively active form of CREB in DRG neurons, promotes regeneration of central DRG branches after a dorsal column lesion (Gao et al., 2004). Moreover, recent work from our laboratory has shown that CREB-mediated signaling is involved in neurite elongation of immature cerebral cortex neurons (Landeira et al., 2016), suggesting that this transcription factor represents a potential target to promote corticospinal axon regeneration.

The role of c-Jun transcription factor in axon regeneration has also been examined. Conditional knockout of c-Jun in facial motor neurons decreases axon regeneration of facial nerves after axotomy (Raivich et al., 2004). Moreover, knockdown of c-Jun in DRG neurons, using in vivo electroporation of siRNA, significantly impairs axon regeneration of peripheral branches after sciatic nerve lesion (Saijilafu et al., 2011), while overexpression of c-Jun in these cells is able to promote neurite outgrowth in vitro (Chandran et al., 2016). Although, c-Jun has a positive effect on axon regeneration, it has been shown that c-Jun expression in required for cell death of facial motoneurons after axotomy as well as in RGC after optic nerve lesion (Yoshida et al., 2002; Raivich et al., 2004; Lingor et al., 2005). Thus, these studies demonstrate that c-Jun, an immediate early gene, has a dual role in neurons, involved in the induction of axon regeneration and neuronal cell death. While deletion of c-Jun impaired axonal regrowth in the CNS and PNS, it remains to be tested whether forced expression of c-Jun improves axon regeneration in the CNS in vivo. In addition, the role of c-Jun on neuronal cell death precludes the use of c-Jun for clinical applications.

The transcription factor ATF3, which can form heterodimer with c-Jun, is also able to increase axonal regrowth in the PNS. In transgenic mice that constitutively express ATF3, there is an increase in axonal regeneration of DRG peripheral branches after injury (Seijffers et al., 2007). However, constitutively expression of ATF3 does not overcome myelin inhibition on neurite outgrowth of DRG in culture or enhance central axon regeneration in the spinal cord after dorsal column injury in vivo (Seijffers et al., 2007). These findings demonstrate that genes involved in axonal regrowth in the PNS are not necessary important for axon regeneration in the CNS. Nevertheless, it remains to be tested whether manipulations of c-Jun and ATF3 are effective in promoting axon growth in different CNS neuronal types after injury. Moreover, whether there is a crosstalk between c-Jun, ATF-3 and others transcription factors like ATF-2, which is relevant to axon regeneration remains to be determined.

SOX11 is an example of transcription factor required for PNS axon growth whose forced expression promotes regeneration in the CNS. SOX11 is highly expressed in the embryonic CNS and PNS, but it is downregulated at later developmental stages (Hargrave et al., 1997; Tanabe et al., 2003; Dy et al., 2008; Penzo-Méndez, 2010). However, its expression in rapidly upregulated in DRG neurons following peripheral axotomy, and its deletion decreases PNS neurite growth (Tanabe et al., 2003; Lin et al., 2011). Recently, Wang and colleagues showed that overexpression of SOX11 in CSNs is sufficient to promote CST compensatory sprouting and axon regeneration after spinal cord injury. The effect of SOX11 forced expression on axon regeneration was observed, although at lesser extent, even when delivered 2 months after injury, indicating that SOX11 is able to promote axon regrowth in both acute and chronic injury paradigms. Despite of that, the normal recovery of forelimb dexterity that occurs after cervical spinal cord injury was impaired in SOX11-treated animals on both injury paradigms (Wang et al., 2015). These data suggest that regenerating axons induced by SOX11 overexpression may not establish functional synapses, or they form synapses with wrong targets, which could prevent functional recovery. Considering the roles of SOX11 in the developing cerebral cortex as an upstream regulator of FEZF2, which is required for the specification of corticospinal neuron identity and connectivity (Shim et al., 
2012; Muralidharan et al., 2017), and as a negative controller of dendritic morphogenesis (Hoshiba et al., 2016), it is possible that sustained expression of SOX11 in adult neurons leads to conflicting effects on axonal regeneration. According to this notion, overexpression of SOX11 in RGCs promotes robust axon regeneration in a subset of RGCs after optic nerve lesion, but also induces cell death in another subtype of RGC (Norsworthy et al., 2017). Future studies should help elucidating whether different levels of SOX11 expression are responsible for those conflicting effects in RGCs. Similarly, it remains to be tested whether a time-controlled expression of SOX11 could lead to robust axon regeneration while avoiding undesired effects.

ASCL1 is a proneural basic helix-loop-helix (bHLH) transcriptional factor involved in cell fate determination and differentiation (Vasconcelos and Castro, 2014). It has been recently shown that ASCL1 is required to axon regeneration of RGCs after optic nerve crush in adult zebrafish. Furthermore, overexpression of ASCL1 in brainstem neurons of rats promotes noradrenergic axon regeneration after spinal cord injury and improves hindlimb movement recovery (Williams et al., 2015). These findings suggest that overexpression of proneural genes in adult neurons after injury could be an interesting strategy to promote axon regeneration in the mammalian CNS. According to this notion, ASCL1 expression upregulates the expression of several genes involved in axonogenesis and axon guidance during neuronal differentiation (Castro et al., 2011; Raposo et al., 2015). Moreover, ASCL1 induces the expression of other transcription factors involved in axon regeneration, such as SOX11 (Masserdotti et al., 2015). Last but not least, binding of ASCL1 to DNA increases chromatin accessibility at regulatory regions of its target genes (Raposo et al., 2015), what could be an interesting mechanism to overcome epigenetic barriers to the expression of pro-regenerative genes after CNS injury.

A recent elegant study points to c-Myc as a pivotal transcription factor controlling axon regeneration and survival of RGC after optic nerve injury. The transcription factor cMyc is a oncogene known to control cell cycle progression, proliferation, growth, adhesion, differentiation, apoptosis, and metabolism (Meyer and Penn, 2008). In adult mice, c-Myc is highly expressed in RGC and it is downregulated after optic nerve crush (Belin et al., 2015). Overexpression of c-Myc promotes RGC survival and axon regeneration after optic nerve crush. As an additional highlight of this study, the authors showed, using a tamoxifen-inducible c-Myc transgenic mouse line, that transient overexpression of c-Myc prior to optic nerve injury promotes both robust neuronal survival and axon regeneration of RGCs. Moreover, c-Myc expression even after injury significantly increases RGC survival and axon regeneration, suggesting that c-Myc can rescue these injured neurons from apoptotic death and promote their axon regeneration (Belin et al., 2015). Although, the authors showed very robust effects of neuronal survival and axon regeneration, additional long-term studies are necessary in order to translate this strategy to the clinics because c-Myc is a well know transcription factor involved in tumorigenesis.

\section{Rho/ROCK}

Although, the main focus of this review is not extracellular inhibitory molecules that block axon regeneration, here we will briefly discuss some studies that manipulate the Rho/ROCK pathway, which is an important intracellular signaling pathway activated by different extracellular inhibitory factors (Shamah et al., 2001; Dontchev and Letourneau, 2003; Lin et al., 2007). Many of these inhibitory components bind to receptors in the axonal membrane and lead to activation of Ras homologous member A (RhoA) resulting in growth cone collapse and axonal retraction (Jalink et al., 1994; Wahl et al., 2000; Gu et al., 2013). The Rho-associated coiled-coil-containing protein kinase (ROCK) has been identified as a main downstream target of RhoA (Ishizaki et al., 1997), which is responsible for propagating this signal to the cytoskeleton, modulating neurite growth and axon regeneration (Moreau-Fauvarque et al., 2003; Mueller et al., 2005). Several studies have used genetic manipulation techniques to modulate this pathway to promote axonal regrowth. Expression of a dominant negative mutant of ROCK promotes neurite outgrowth of DRG neurons cultured on myelin substrate. In addition, expression of this dominant negative mutant in rubrospinal neurons enhances axon regeneration of rubrospinal tract (RST) axons after cervical spinal cord injury. Importantly, this was accompanied by recovery of forelimb and hindlimb functions (Wu et al., 2009). Focusing on the same neuronal type, we have shown that post-injury knockdown of ROCK2, using a shRNA against it, promotes rubrospinal neuron survival and prevents atrophy after spinal cord hemisection (Challagundla et al., 2015). Moreover, knockdown of ROCK2 enhances RST axonal sprouting proximal to the lesion. However, in this study ROCK2 downregulation did not increase axon regeneration distal to the lesion and only promotes minimal recovery in hindlimb motor behavior (Challagundla et al., 2015). In the visual system, knockdown of ROCK2 enhances neurite outgrowth of RGCs cultured on inhibitory substrates. Furthermore, knockdown of ROCK2 induces substantial axonal regeneration, increases survival of RGCs and attenuates axonal degeneration of proximal axons after optic nerve injury assessed by in vivo live imaging (Koch et al., 2014a). In addition to ROCK, downregulation of RhoA has beneficial effects on neuronal survival and regeneration. Knockdown of RhoA promotes neurite outgrowth of RGC neurons cultured on inhibitory substrate as well as neurite regeneration of primary midbrain neurons after scratch lesion. Besides that, downregulation of RhoA significantly enhances axonal regeneration and survival of RGCs after optic nerve lesion (Koch et al., 2014b). Taken together, these findings imply that the Rho/ROCK pathway may be an interesting molecular target for the treatment of traumatic CNS injury.

Considering the broad roles of RhoA/ROCK pathway in the control of cell proliferation, specification, survival and migration (Cappello, 2013; Duquette and Lamarche-Vane, 2014), it is possible that direct downregulation of RhoA or ROCK may lead to undesired effects. However, new approaches to interfere with specific effects of that pathway on axonal growth could be designed in the future. According to this notion, it has been 


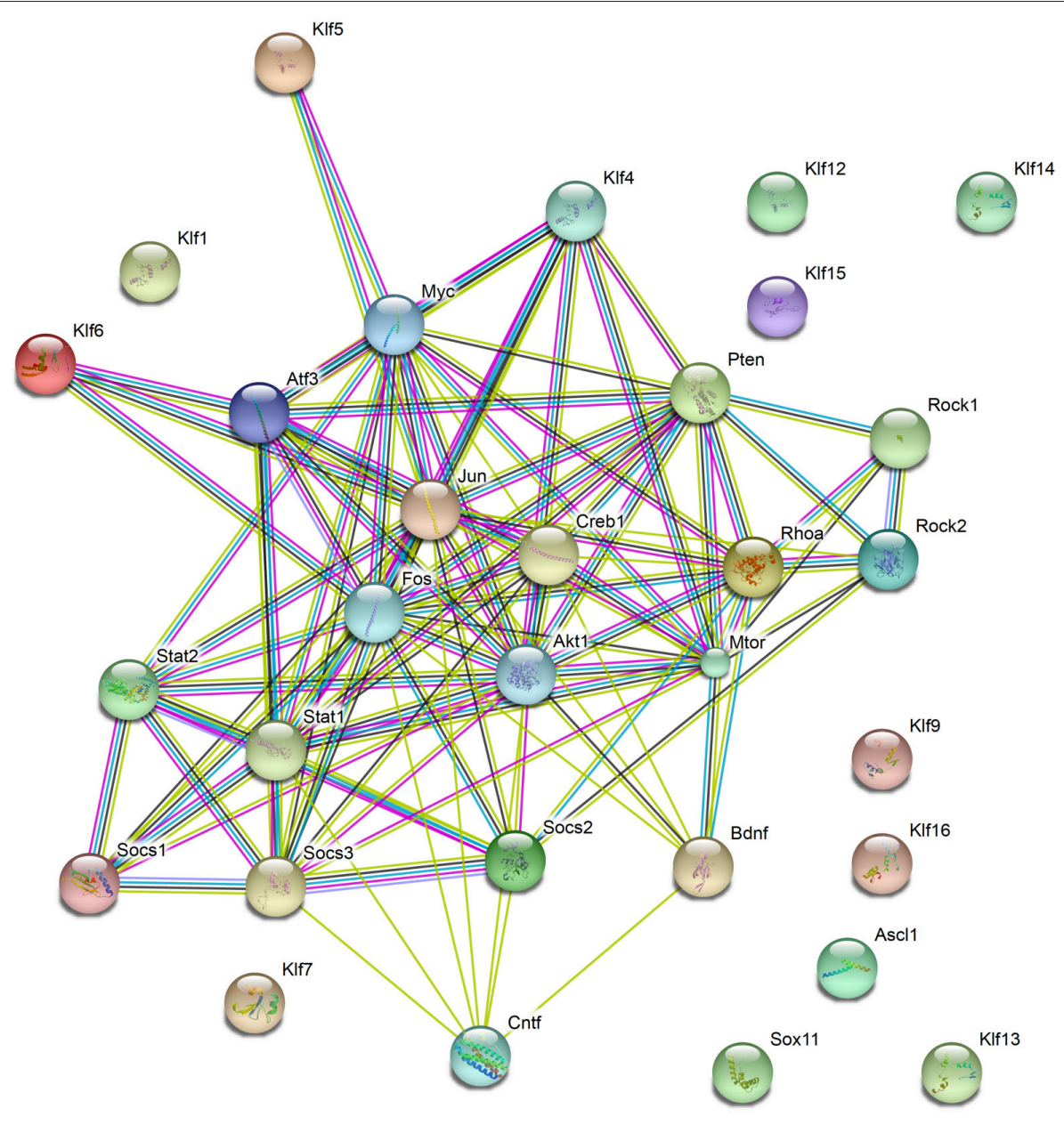

FIGURE 2 | Functional protein networks involved in axon regeneration. Schematic representation of interactions among proteins manipulated to stimulate CNS axon regeneration and discussed in this work. Nodes show the proteins described throughout the work. Observe that most proteins show some direct or indirect interaction, except the transcription factors SOX11, ASCL1, and members of the KLF family (KLF1, 7, 12, 13, 14, 15, 16, and 19). Edges represent protein-protein associations, as follows: Known interactions - Light blue (from curated databases) and purple (experimentally determined); Predicted interactions-dark green (gene neighborhood), red (gene fusions), and dark blue (gene co-occurrence); Others-light green (text-mining), black (co-expression), and cyan (protein homology). Observe that most proteins coded by genes manipulated in previous work show some degree of association. The total number of edges is 104 , whereas the expected number of edges for a random set of proteins of similar size is 24 , indicating that the proteins are at least partially biologically connected, as a group.

shown that the ubiquitin E3 ligase Smad Ubiquitin Regulatory Factor 1 (Smurf1) is phosphorylated at Threonin 306 by PKA after BDNF treatment of hippocampal and cerebral cortex neurons. This phosphorylated form of Smurf1 then reduces degradation of polarity protein Par6 and increases degradation of growth-inhibiting RhoA, leading to neuronal polarity and axon initiation (Cheng et al., 2011). These observations suggest that site-specific phosphorylation of ubiquitin E3 ligases could be a useful mechanism for establishing specific spatiotemporal patterns of RhoA/ROCK (and other proteins) expression that are required for axonal growth without interfering with other cell functions.

\section{COMBINATORIAL STRATEGIES}

Genetic manipulations of single targets genes promote some degree of axon regrowth in different types of neurons (Table 1;
Figure 1). Still, functional recovery has been limited, indicating that combinatorial approaches may be necessary to induce robust axon regeneration, synapse formation and myelination, all required for efficient propagation of neuronal signals and functional recovery. Interestingly, most genes manipulated in experimental protocols aiming at boosting axonal regeneration show some degree of interaction (Figure 2) and are involved in the positive regulation of macromolecules biosynthesis (GO: 0010557). The transcription factors ASCL1 and SOX11 are exceptions to this rule, suggesting that these proteins may elicit axonal regeneration through a distinct mechanism.

The crosstalk among proteins involved in axon regeneration may help to explain the additional beneficial effects of combinatorial genetic manipulations on axon regeneration and neuronal survival. Indeed, co-deletion of PTEN and SOCS3, has produced one of the most robust effects on axon regrowth to date. While single deletion of either PTEN or SOCS3 induces axon 
regeneration of the optic nerve up to $2-3 \mathrm{~mm}$ distal to the lesion, co-deletion of PTEN and SOCS3 results in more than ten-fold increase in the number of regenerating axons at $2 \mathrm{~mm}$ distal to the lesion compared with deletion of either gene alone (Sun et al., 2011). Moreover, in the double mutants, a substantial number of regenerating axons reached the optic chiasm and several could grow even further, reaching the optic-tract brain entry zone, the hypothalamus and the suprachiasmatic nuclei area. In addition to axon regeneration, co-deletion of PTEN and SOCS3 also significantly enhances RGC survival compared to single deletion (Sun et al., 2011). In the spinal cord, deletion of SOCS3 promotes sprouting of uninjured CST axons after unilateral pyramidotomy, an effect that can be further enhanced by co-deletion of PTEN, resulting in significant recovery of skilled locomotion (Jin et al., 2015). These findings suggest that PTEN/mTOR and SOCS3/JAK/STAT3 pathways act synergistically to promote axon regeneration, sprouting and neuronal survival and point to these pathways as potential targets for combined manipulation in order to promote functional recovery. However, as mentioned before, both pathways are involved in tumorigenesis, thus long-term studies are necessary to prove the safety of PTEN and SOCS3 co-deletion.

Combinatorial modulation of SOCS3 and KLF family member of transcription factors have also promoted additional effects on axon regeneration. Qin and colleagues showed that conditional deletion of SOCS3 promotes axon regeneration after optic nerve lesion, which is further enhanced by co-deletion of KLF4. While in this study the authors observed beneficial effects of double-deletion on axon regeneration, RGC survival was not improved (Qin et al., 2013). However, in KLF4-deleted animals, intravitreal injection of CNTF, a well know cytokine that activates the JAK/STAT3 pathway, dramatic enhances axon regrowth and, interestingly, results in a significant increase in the survival of injured RGCs. Moreover, the authors showed that KLF4 physically interacts with STAT3 and suppresses STAT3dependent gene expression (Qin et al., 2013). Therefore, these findings indicate a crosstalk between KLF4 and STAT3 that could be manipulated in a synergistic fashion to promote axon regrowth and neuronal survival.

In the same direction, Belin and colleagues observed that simultaneous overexpression of c-Myc and deletion of PTEN further increase axon regrowth and RGC survival compared with either strategy alone. The combination of PTEN and SOCS3 deletion with overexpression of CNTF and c-Myc promotes robust regeneration of injured optic nerve axons, with a five-fold increase in the number of regenerating axons at the proximal end of the optic chiasm, compared with co-deletion of PTEN and SOCS3 and overexpression of CNTF only (Belin et al., 2015). Despite the impressive regenerating effect obtained by this combinatorial approach, one important issue raised in this study was that regenerating axons also projected ectopically into the contralateral optic nerve, suggesting possible guidance problems. Using the visual system, Pernet and colleagues have shown that ROCK is an important protein involved in the control of axonal growth direction. Overexpression of STAT3 in RGC promotes axonal regeneration in the injured optic nerve. However, analysis of whole-mounted optic nerves in three dimensions showed that the regenerating axons displayed irregular courses, suggesting axonal misguidance. Pharmacological inhibition of ROCK reduced the misguidance issues of regenerating axons and improved long-distance axon regeneration of RGCs overexpressing STAT3 (Pernet et al., 2013), suggesting that correcting direction problems is an important step toward robust axon regeneration and pointing to ROCK as a pivotal target. It will be interesting to test in the future whether the manipulation of ROCK could improve the directional issues observed in the study by Belin and co-workers. Nevertheless, these work manipulated proteins involved in tumorigenesis, namely PTEN, SOCS3, and c-Myc, which again raises important concerns regarding the potential long-term effects of this manipulation.

Recently, combination of neuronal electrical stimulation and expression of proteins that promote axon regrowth has emerged as an alternative to boost regeneration. Enhancement of RGCs electrical activity using chemogenetic tools promotes axon regeneration after optic nerve lesion (Lim et al., 2016). Combination of increased RGC activity, by high-contrast visual stimulation, with genetic activation of the mTOR pathway promotes extensive axon regeneration (Lim et al., 2016). Moreover, triple combination of high-contrast visual stimulation, mTOR activation, and removal of the visual input from the intact eye (i.e., forcing the use of lesioned eye) leads to the regrowth of RGC axons along the entire optic pathway (Lim et al., 2016). In this combinatorial strategy, regenerating axons avoided incorrect targets and projected to their normal target nuclei partially rescuing visual behavior (Lim et al., 2016). These impressive findings show the importance of mTOR activation and, more interesting, the importance of neuronal activity to promote long distance axon regeneration and reconnection with the correct targets. Nonetheless, the number of axons that find their correct target is insufficient to promote complete recovery, indicating that additional advances are still necessary.

In addition to long-distance regeneration and reconnection to proper targets, re-myelination is also an import step to promote functional recovery. Manipulation of PTEN and SOCS3 expression robustly promotes axon regrowth and formation of functional synapses in the superior colliculus, but fails to produce significant recovery of visual function. This failure can be partly explained by the lack of myelination in regenerated axons, which exhibit poor electrical conductance. Accordingly, application of voltage-gated potassium channel blockers restores conduction and promotes recovery of behavioral functions (Bei et al., 2016). Thus, proper myelination of regenerating axons is a crucial step to improve nerve conduction to ultimately achieve functional recovery after injuries to the CNS.

\section{PERSPECTIVES}

In the last decade, many efforts have been made to uncover the signaling pathways and networks involved in axon growth in the injured CNS. The use of different strategies to modulate gene expression, such as transgenic animals and viral vectors, provided useful tools to analyze the role of specific proteins 
TABLE 2 | First 20 functional enrichments in the network shown in Figure 2 using Biological Process Gene Ontology (GO) and Kyoto Encyclopedia of Genes and Genomes (KEGG) Pathways.

\begin{tabular}{|c|c|c|c|c|}
\hline \#Pathway ID & Pathway description & $\begin{array}{l}\text { Observed } \\
\text { gene count }\end{array}$ & $\begin{array}{l}\text { False } \\
\text { discovery rate }\end{array}$ & Matching proteins in your network (labels) \\
\hline \multicolumn{5}{|c|}{ BIOLOGICAL PROCESS GENE ONTOLOGY (GO) } \\
\hline G0.0010557 & Positive regulation of macromolecule biosynthetic process & 20 & $9.39 \mathrm{e}-13$ & $\begin{array}{l}\text { Akt1,Ascl1,Atf3,Bdnf,Fos,Klf1,Klf12,Klf13,Klf14,Klf15, } \\
\text { Klf4,Klf5,Klf7,Klf9,Mtor, Myc, } \\
\text { Pten,Rhoa,Sox11,Stat1 }\end{array}$ \\
\hline G0.0010628 & Positive regulation of gene expression & 20 & $9.39 e-13$ & $\begin{array}{l}\text { Akt1,Ascl1,Atf3,Bdnf,Fos,Klf1,Klf12,Klf13,Klf14,Klf15, } \\
\text { Klf4,Klf5,Klf7,Klf9,Mtor,Myc,Pten,Rhoa,Sox11,Stat1 }\end{array}$ \\
\hline G0.0045893 & Positive regulation of transcription, DNA-templated & 19 & $9.39 \mathrm{e}-13$ & $\begin{array}{l}\text { Akt1,Ascl1,Atf3,Bdnf,Fos,Klf1,Klf12,Klf13,Klf14,Klf15, } \\
\text { Klf4,Klf5,Klf7,Klf9,Mtor,Myc,Pten,Sox11,Stat1 }\end{array}$ \\
\hline GO.0031328 & Positive regulation of cellular biosynthetic process & 20 & $9.56 e-13$ & $\begin{array}{l}\text { Akt1,Ascl1,Atf3,Bdnf,Fos,Klf1,Klf12,Klf13,Klf14,Klf15, } \\
\text { Klf4,Klf5,Klf7,Klf9,Mtor,Myc,Pten,Rhoa,Sox11,Stat1 }\end{array}$ \\
\hline GO.0045595 & Regulation of cell differentiation & 19 & $9.56 \mathrm{e}-13$ & $\begin{array}{l}\text { Akt1,Ascl1,Bdnf,Cntf,Creb1,Fos,Klf13,Klf4,Klf5,Mtor, } \\
\text { Myc,Pten,Rhoa,Rock1,Rock2,Socs2,Socs3,Sox11,Stat1 }\end{array}$ \\
\hline GO.0051173 & $\begin{array}{l}\text { Positive regulation of nitrogen compound metabolic } \\
\text { process }\end{array}$ & 20 & $9.56 \mathrm{e}-13$ & $\begin{array}{l}\text { Akt1,Ascl1,Atf3,Bdnf,Fos,Klf1,Klf12,Klf13,Klf14,Klf15, } \\
\text { Klf4,Klf5,Klf7,Klf9,Mtor,Myc,Pten,Rhoa,Sox11,Stat1 }\end{array}$ \\
\hline GO.0006355 & Regulation of transcription, DNA-templated & 23 & $2.09 \mathrm{e}-12$ & $\begin{array}{l}\text { Akt1,Ascl1,Atf3,Bdnf,Fos,Klf1,Klf12,Klf13,Klf14,Klf15, } \\
\text { Klf16,Klf4,Klf5,Klf6,Klf7,Klf9,Mtor,Myc,Pten,Rhoa,Sox11, } \\
\text { Stat1,Stat2 }\end{array}$ \\
\hline G0.0031325 & Positive regulation of cellular metabolic process & 22 & $8.17 \mathrm{e}-12$ & $\begin{array}{l}\text { Akt1,Ascl1,Atf3,Bdnf,Cntf,Fos,Klf1,Klf12,Klf13,Klf14,Klf15, } \\
\text { Klf4,Klf5,Klf7,Klf9,Mtor,Myc,Pten,Rhoa,Sox11,Stat1,Stat2 }\end{array}$ \\
\hline GO.0007166 & Cell surface receptor signaling pathway & 18 & $9.16 \mathrm{e}-12$ & $\begin{array}{l}\text { Akt1,Ascl1,Bdnf,Cntf,Cntfr,Creb1,Fos,Jun,Klf4,Klf6,Myc, } \\
\text { Rhoa,Rock2,Socs1,Socs2,Socs3,Stat1,Stat2 }\end{array}$ \\
\hline GO.0006351 & Transcription, DNA-templated & 20 & $1.03 e-11$ & $\begin{array}{l}\text { Ascl1,Atf3,Creb1,Fos,Jun,Klf1,Klf12,Klf13,Klf14,Klf15, } \\
\text { Klf16,Klf4,Klf5,Klf6,Klf7,Klf9,Myc,Sox11,Stat1,Stat2 }\end{array}$ \\
\hline GO.0010243 & Response to organonitrogen compound & 14 & $1.03 e-11$ & $\begin{array}{l}\text { Akt1,Ascl1,Creb1,Fos,Jun,Klf15,Klf4,Mtor,Myc,Pten,Rhoa, } \\
\text { Socs2,Socs3,Stat1 }\end{array}$ \\
\hline G0.0018130 & Heterocycle biosynthetic process & 21 & $1.03 e-11$ & $\begin{array}{l}\text { Ascl1,Atf3,Creb1,Fos,Jun,Klf1,Klf12,Klf13,Klf14,Klf15, } \\
\text { Klf16,Klf4,Klf5,Klf6,Klf7,Klf9,Mtor,Myc,Sox11,Stat1,Stat2 }\end{array}$ \\
\hline G0.0044271 & Cellular nitrogen compound biosynthetic process & 22 & $1.03 e-11$ & $\begin{array}{l}\text { Akt1,Ascl1,Atf3,Creb1,Fos,Jun,Klf1,Klf12,Klf13,Klf14, } \\
\text { Klf15,Klf16,Klf4,Klf5,Klf6,Klf7,Klf9,Mtor,Myc,Sox11,Stat1, } \\
\text { Stat2 }\end{array}$ \\
\hline G0.0048519 & Negative regulation of biological process & 25 & $1.03 e-11$ & $\begin{array}{l}\text { Ascl1,Atf3,Bdnf,Cntf,Cntfr,Creb1,Jun,Klf12,Klf13,Klf14, } \\
\text { Klf15,Klf16,Klf4,Klf5,Klf9,Mtor,Myc,Pten,Rhoa,Rock1, } \\
\text { Rock2,Socs1,Socs2,Socs3,Stat1 }\end{array}$ \\
\hline G0.0048522 & Positive regulation of cellular process & 25 & $1.96 \mathrm{e}-11$ & $\begin{array}{l}\text { Ascl1,Atf3,Bdnf,Cntf,Cntfr,Fos, Klf1,Klf12,Klf13,Klf14,Klf15, } \\
\text { Klf4,Klf5,Klf7,Klf9,Myc,Pten,Rhoa,Rock1,Rock2,Socs2, } \\
\text { Socs3,Sox11,Stat1,Stat2 }\end{array}$ \\
\hline GO.0048523 & Negative regulation of cellular process & 24 & $2.03 e-11$ & $\begin{array}{l}\text { Ascl1,Atf3,Bdnf,Cntf,Cntfr,Creb1,Jun,Klf12,Klf13,Klf14, } \\
\text { Klf15,Klf16,Klf4,Klf5,Klf9,Mtor,Myc,Pten,Rhoa,Rock1, } \\
\text { Socs1,Socs2,Socs3,Stat1 }\end{array}$ \\
\hline GO.1901362 & Organic cyclic compound biosynthetic process & 21 & $2.04 \mathrm{e}-11$ & $\begin{array}{l}\text { Ascl1,Atf3,Creb1,Fos,Jun,Klf1,Klf12,Klf13,Klf14,Klf15, } \\
\text { Klf16,Klf4,Klf5,Klf6,Klf7,Klf9,Mtor,Myc,Sox11,Stat1,Stat2 }\end{array}$ \\
\hline G0.2000026 & Regulation of multicellular organismal development & 18 & $2.09 e-11$ & $\begin{array}{l}\text { Akt1,Ascl1,Bdnf,Cntf,Creb1,Fos,Jun,Klf13,Klf4,Mtor,Myc, } \\
\text { Pten,Rhoa,Rock1,Rock2,Socs2,Sox11,Stat1 }\end{array}$ \\
\hline G0.0010604 & Positive regulation of macromolecule metabolic process & 21 & $2.21 \mathrm{e}-11$ & $\begin{array}{l}\text { Akt1,Ascl1,Atf3,Bdnf,Cntf,Fos,Klf1,Klf12,Klf13,Klf14,Klf15, } \\
\text { Klf4,Klf5,Klf7,Klf9,Mtor,Myc,Pten,Rhoa,Sox11,Stat1 }\end{array}$ \\
\hline G0.0030154 & Cell differentiation & 22 & $1.23 \mathrm{e}-10$ & $\begin{array}{l}\text { Akt1,Atf3,Bdnf,Cntf,Creb1,Fos,Jun,Klf1, Klf15,Klf4,Klf5, } \\
\text { Klf7,Mtor,Myc,Pten,Rhoa,Rock1,Rock2,Socs1,Socs2, } \\
\text { Socs3,Stat1 }\end{array}$ \\
\hline \multicolumn{5}{|c|}{ KYOTO ENCYCLOPEDIA OF GENES AND GENOMES (KEGG) PATHWAYS } \\
\hline 4380 & Osteoclast differentiation & 8 & $1.5 e-09$ & Akt1,Creb1,Fos,Jun,Socs1,Socs3,Stat1,Stat2 \\
\hline 4630 & JAK-STAT signaling pathway & 8 & $2.65 e-09$ & Akt1,Cntf,Cntfr,Myc,Socs1,Socs3,Stat1,Stat2 \\
\hline 5161 & Hepatitis B & 8 & $2.65 \mathrm{e}-09$ & Akt1,Creb1,Fos,Jun,Myc,Pten,Stat1,Stat2 \\
\hline 5200 & Pathways in cancer & 8 & $7.84 \mathrm{e}-07$ & Akt1,Fos,Jun,Mtor,Myc,Pten,Rhoa,Stat1 \\
\hline 5210 & Colorectal cancer & 5 & $1.52 \mathrm{e}-06$ & Akt1,Fos,Jun,Myc,Rhoa \\
\hline
\end{tabular}


TABLE 2 | Continued

\begin{tabular}{llccl}
\hline \#Pathway ID & Pathway description & $\begin{array}{c}\text { Observed } \\
\text { gene count }\end{array}$ & $\begin{array}{c}\text { False } \\
\text { discovery rate }\end{array}$ & Matching proteins in your network (labels) \\
\hline 5206 & MicroRNAs in cancer & 6 & $1.79 e-06$ & Mtor,Myc,Pten,Rhoa,Rock1,Socs1 \\
4917 & Prolactin signaling pathway & 5 & $2.47 e-06$ & Akt1,Fos,Socs1,Socs3,Stat1 \\
4062 & Chemokine signaling pathway & 6 & $5.66 \mathrm{e}-06$ & Akt1,Rhoa,Rock1,Rock2,Stat1,Stat2 \\
4510 & Focal adhesion & 6 & $1.15 \mathrm{e}-05$ & Akt1,Jun,Pten,Rhoa,Rock1,Rock2 \\
4668 & TNF signaling pathway & 5 & $1.15 \mathrm{e}-05$ & Akt1,Creb1,Fos,Jun,Socs3 \\
5205 & Proteoglycans in cancer & 6 & $1.44 \mathrm{e}-05$ & Akt1,Mtor,Myc,Rhoa,Rock1,Rock2 \\
5166 & HTLV-I infection & 6 & $4.01 \mathrm{e}-05$ & Akt1,Atf3,Creb1,Fos,Jun,Myc \\
4921 & Oxytocin signaling pathway & 5 & $5.14 \mathrm{e}-05$ & Fos,Jun,Rhoa,Rock1,Rock2 \\
4022 & cGMP-PKG signaling pathway & 5 & $6.83 e-05$ & Akt1,Creb1,Rhoa,Rock1,Rock2 \\
5164 & Influenza A & 5 & $6.83 \mathrm{e}-05$ & Akt1,Jun,Socs3,Stat1,Stat2 \\
5132 & Salmonella infection & 4 & $7.69 \mathrm{e}-05$ & Fos,Jun,Rock1,Rock2 \\
4012 & ErbB signaling pathway & 4 & $9.74 \mathrm{e}-05$ & Akt1,Jun,Mtor,Myc \\
5215 & Prostate cancer & 4 & 0.000111 & Akt1,Creb1,Mtor,Pten \\
5168 & Herpes simplex infection & 5 & 0.000114 & Fos,Jun,Socs3,Stat1,Stat2 \\
4915 & Estrogen signaling pathway & 4 & 0.00013 & Akt1,Creb1,Fos,Jun \\
\hline
\end{tabular}

in a variety of events during neuronal regeneration. Moreover, the possibility of temporal control of gene expression, using the CreERT/Tamoxifen system, can allow the evaluation of the role of specific molecules at different time-points after CNS injury. Finally, the use of AAV-mediated transduction to manipulate target genes in adult neurons after CNS injury and stimulate axon regeneration represents a fundamental step toward the translation of these techniques into clinic. Because of all advantages, including the ability to efficiently target various cell types in the CNS, the excellent safety profile and low immunogenicity that allows for long-term expression of the transgene after a single administration, recombinant AAV vectors are the most suited vector for gene manipulation in the CNS, which include the delivery of therapeutic genes or the Cre into transgenic animals to either overexpress or delete specific genes. Moreover, we believe that AAV are currently the most favored vectors for gene therapy in the injured CNS.

Optic nerve lesion and spinal cord injury are the most used experimental models employed to investigate the role of specific genes in axon regeneration in the CNS. The optic nerve lesion has many experimental advantages that facilitate the use of genetic tools and evaluation of the effects. On the other hand, spinal cord injury is more important clinically. Although, both models have advantages and disadvantages, both are very useful models to employ genetic techniques and identify genes involved in the control of axon regrowth.

Yet, although several groups identified many potential candidates to promote axon regrowth, our current understanding of the biological processes driving axon regeneration is still relatively limited, demonstrating that additional studies are necessary for a more accurate view of the mechanisms and synergistic effects of molecules controlling axon growth. Up to date, most molecular pathways tested in the adult CNS are involved in general processes of macromolecule biosynthesis and cell differentiation (Table 2). However, these processes are not specific for neurons and are often associated with cancer
(Table 2). Thus, the identification of molecular mechanisms specific for axon growth, if they may exist, will likely contribute to the design of more efficient and safer strategies to promote CNS repair.

We believe that a more comprehensive knowledge about the molecular control of axon elongation, axon guidance, synaptic formation, and myelination in the developing CNS may further contribute to this goal. As discussed in previous sections, the developmental decline in the capacity for axon growth in the CNS is associated with numerous changes in gene expression, pointing to the developing CNS as an interesting model to identify new targets involved in axon growth, in particular molecules controlling gene expression programs, i.e., transcription factors. Genetic manipulation of transcription factors that act as master key regulators of axon elongation during development might represent a valuable strategy for promoting axon regeneration in adults.

In addition to the identification of new targets, modifications of previous strategies to avoid undesired side effects should also be considered. For example, genetic tools designed to temporally control the expression of selected transcription factors, such as SOX11, may allow the stimulation of axon growth and by-pass the undesired effect of cell death. Similar approaches may be considered to the combination of PTEN, SOCS3, and c-Myc, which leads to a robust axon growth but are also associated with tumor formation. Therefore, long-term studies employing temporal control of gene expression are necessary to establish the efficiency and safety of such strategies to promote axon regeneration.

Last but not least, blocking axonal degeneration improves the ability of axons to regenerate past a lesion site (Ribas et al., 2017), demonstrating that axonal stabilization could be an interesting strategy to facilitate axon regeneration. Moreover, in addition to promote robust axon regeneration, other events, such as axon guidance to correct targets, establishment of functional synapses, and remyelination, are also important to successfully 
restore neuronal function. This is still a long road that will require many additional advances in our understanding of how different intrinsic and extrinsic signals interact to generate a precisely wired CNS. In sum, we advocate that the identification of key molecular players for axon growth and guidance during development, as well as a systematic analysis of their effects in the adult CNS after injury, will contribute to the design of successful therapeutic interventions aiming at the repair of the injured CNS in conditions of neurodegenerative diseases or physical trauma.

\section{REFERENCES}

Acland, G. M., Aguirre, G. D., Bennett, J., Aleman, T. S., Cideciyan, A. V., Bennicelli, J., Dejneka, N. S., et al. (2005). Long-term restoration of rod and cone vision by single dose rAAV-mediated gene transfer to the retina in a canine model of childhood blindness. Mol. Ther. 12, 1072-1082. doi: 10.1016/j.ymthe.2005.08.008

Aguayo, A. J., David, S., and Bray, G. M. (1981). Influences of the glial environment on the elongation of axons after injury: transplantation studies in adult rodents. J. Exp. Biol. 95, 231-240.

Allocca, M., Mussolino, C., Garcia-Hoyos, M., Sanges, D., Iodice, C., Petrillo, M., et al. (2007). Novel adeno-associated virus serotypes efficiently transduce murine photoreceptors. J. Virol. 81, 11372-11380. doi: 10.1128/JVI.01327-07

Auricchio, A., Kobinger, G., Anand, V., Hildinger, M., O’Connor, E., Maguire, A. M., et al. (2001). Exchange of surface proteins impacts on viral vector cellular specificity and transduction characteristics: the retina as a model. Hum. Mol. Genet. 10, 3075-3081. doi: 10.1093/hmg/10.26.3075

Bandtlow, C. E., and Löschinger, J. (1997). Developmental changes in neuronal responsiveness to the CNS myelin-associated neurite growth inhibitor NI35/250. Eur. J. Neurosci. 9, 2743-2752. doi: 10.1111/j.1460-9568.1997.tb01703.x

Bareyre, F. M., Garzorz, N., Lang, C., Misgeld, T., Büning, H., and Kerschensteiner, M. (2011). In vivo imaging reveals a phase-specific role of STAT3 during central and peripheral nervous system axon regeneration. Proc. Natl. Acad. Sci. U.S.A. 108, 6282-6287. doi: 10.1073/pnas. 1015239108

Bei, F., Lee, H. H. C., Liu, X., Gunner, G., Jin, H., Ma, L., et al. (2016). Restoration of visual function by enhancing conduction in regenerated axons. Cell 164, 219-232. doi: 10.1016/j.cell.2015.11.036

Belin, S., Nawabi, H., Wang, C., Tang, S., Latremoliere, A., Warren, P., et al. (2015). Injury-induced decline of intrinsic regenerative ability revealed by quantitative proteomics. Neuron 86, 1000-1014. doi: 10.1016/j.neuron.2015.03.060

Bennett, J. (2003). Immune response following intraocular delivery of recombinant viral vectors. Gene Ther. 10, 977-982. doi: 10.1038/sj.gt.3302030

Berns, K. I., and Giraud, C. (1996). Biology of adeno-associated virus. Curr. Top. Microbiol. Immunol. 218, 1-23. doi: 10.1007/978-3-642-80207-2_1

Blackmore, M. G., Wang, Z., Lerch, J. K., Motti, D., Zhang, Y. P., Shields, C. B., et al. (2012). Krüppel-like Factor 7 engineered for transcriptional activation promotes axon regeneration in the adult corticospinal tract. Proc. Natl. Acad. Sci. U.S.A. 109, 7517-7522. doi: 10.1073/pnas.1120684109

Bonni, A., Sun, Y., Nadal-Vicens, M., Bhatt, A., Frank, D. A., Rozovsky, I., et al. (1997). Regulation of gliogenesis in the central nervous system by the JAK-STAT signaling pathway. Science 278, 477-483. doi: $10.1126 /$ science. 278.5337 .477

Burger, C., Nash, K., and Mandel, R. J. (2005). Recombinant adeno-associated viral vectors in the nervous system. Hum. Gene Ther. 16, 781-791. doi: 10.1089/hum.2005.16.781

Cappello, S. (2013). Small Rho-GTPases and cortical malformations: fine-tuning the cytoskeleton stability. Small GTPases 4, 51-56. doi: 10.4161/sgtp.23093

Carnero, A. (2010). The PKB/AKT pathway in cancer. Curr. Pharm. Des. 16, 34-44. doi: $10.2174 / 138161210789941865$

Case, L. C., and Tessier-Lavigne, M. (2005). Regeneration of the adult central nervous system. Curr. Biol. 15, R749-R753. doi: 10.1016/j.cub.2005.09.008

\section{AUTHOR CONTRIBUTIONS}

VR and MC designed, wrote, revised, and finalized the manuscript. All authors read and approved the final version of the manuscript.

\section{ACKNOWLEDGMENTS}

We thank Prof. Tarcisio Velho for the suggestions and helping in proofreading the manuscript.

Castro, D. S., Martynoga, B., Parras, C., Ramesh, V., Pacary, E., Johnston, C., et al. (2011). A novel function of the proneural factor Ascl1 in progenitor proliferation identified by genome-wide characterization of its targets. Genes Dev. 25, 930-945. doi: 10.1101/gad.627811

Cearley, C. N., and Wolfe, J. H. (2006). Transduction characteristics of adenoassociated virus vectors expressing cap serotypes 7, 8, 9, and Rh10 in the mouse brain. Mol. Ther. 13, 528-537. doi: 10.1016/j.ymthe.2005.11.015

Challagundla, M., Koch, J. C., Ribas, V. T., Michel, U., Kügler, S., Ostendorf, T., Bradke, F., et al. (2015). AAV-mediated expression of BAG1 and ROCK2shRNA promote neuronal survival and axonal sprouting in a rat model of rubrospinal tract injury. J. Neurochem. 134, 261-275. doi: 10.1111/jnc.13102

Chandran, V., Coppola, G., Nawabi, H., Omura, T., Versano, R., Huebner, E. A., et al. (2016). A systems-level analysis of the peripheral nerve intrinsic axonal growth program. Neuron 89, 956-970. doi: 10.1016/j.neuron.2016.01.034

Cheng, P., Lu, H., Shelly, M., Gao, H., and Poo, M. (2011). Phosphorylation of E3 ligase Smurf1 switches its substrate preference in support of axon development. Neuron 69, 231-243. doi: 10.1016/j.neuron.2010.12.021

Chong, Z. Z., Shang, Y. C., Wang, S., and Maiese, K. (2012). A critical kinase cascade in neurological disorders: PI 3-K, Akt, and mTOR. Future Neurol. 7, 733-748. doi: $10.2217 /$ fnl.12.72

Cideciyan, A. V., Hauswirth, W. W., Aleman, T. S., Kaushal, S., Schwartz, S. B., Boye, S. L., et al. (2009). Human RPE65 gene therapy for Leber congenital amaurosis: persistence of early visual improvements and safety at 1 year. Hum. Gene Ther. 20, 999-1004. doi: 10.1089/hum.2009.086

Danilov, C. A., and Steward, O. (2015). Conditional genetic deletion of PTEN after a spinal cord injury enhances regenerative growth of CST axons and motor function recovery in mice. Exp. Neurol. 266, 147-160. doi: 10.1016/j.expneurol.2015.02.012

Darnell, J. E., Kerr, I. M., and Stark, G. R. (1994). Jak-STAT pathways and transcriptional activation in response to IFNs and other extracellular signaling proteins. Science 264, 1415-1421. doi: 10.1126/science.8197455

David, S., and Aguayo, A. J. (1981). Axonal elongation into peripheral nervous system "bridges" after central nervous system injury in adult rats. Science 214, 931-933. doi: 10.1126/science.6171034

Dejneka, N. S., Surace, E. M., Aleman, T. S., Cideciyan, A. V., Lyubarsky, A., Savchenko, A., et al. (2004). In utero gene therapy rescues vision in a murine model of congenital blindness. Mol. Ther. 9, 182-188. doi: 10.1016/j.ymthe.2003.11.013

Desclaux, M., Teigell, M., Amar, L., Vogel, R., Gimenez y Ribotta, M., Privat, A., et al. (2009). A novel and efficient gene transfer strategy reduces glial reactivity and improves neuronal survival and axonal growth in vitro. PLoS ONE 4:e6227. doi: 10.1371/journal.pone.0006227

Dontchev, V. D., and Letourneau, P. C. (2003). Growth cones integrate signaling from multiple guidance cues. J. Histochem. Cytochem. 51, 435-444. doi: 10.1177/002215540305100405

Drinjakovic, J., Jung, H., Campbell, D. S., Strochlic, L., Dwivedy, A., and Holt, C. E. (2010). E3 ligase Nedd4 promotes axon branching by downregulating PTEN. Neuron 65, 341-357. doi: 10.1016/j.neuron.2010.01.017

Du, K., Zheng, S., Zhang, Q., Li, S., Gao, X., Wang, J., et al. (2015). Pten deletion promotes regrowth of corticospinal tract axons 1 year after spinal cord injury. J. Neurosci. 35, 9754-9763. doi: 10.1523/JNEUROSCI.3637-14.2015 
Duquette, P. M., and Lamarche-Vane, N. (2014). Rho GTPases in embryonic development. Small GTPases 5:8. doi: 10.4161/sgtp.29716

Dy, P., Penzo-Mendez, A., Wang, H., Pedraza, C. E., MacKlin, W. B., and Lefebvre, V. (2008). The three SoxC proteins-Sox4, Sox11 and Sox12-exhibit overlapping expression patterns and molecular properties. Nucleic Acids Res. 36, 3101-3117. doi: 10.1093/nar/gkn162

Fitch, M. T., and Silver, J. (2008). CNS injury, glial scars, and inflammation: inhibitory extracellular matrices and regeneration failure. Exp. Neurol. 209, 294-301. doi: 10.1016/j.expneurol.2007.05.014

Gao, Y., Deng, K., Hou, J., Bryson, J. B., Barco, A., Nikulina, E., et al. (2004). Activated CREB is sufficient to overcome inhibitors in myelin and promote spinal axon regeneration in vivo. Neuron 44, 609-621. doi: 10.1016/j.neuron.2004.10.030

Geoffroy, C. G., Lorenzana, A. O., Kwan, J. P., Lin, K., Ghassemi, O., Ma, A., $\mathrm{Xu}, \mathrm{N}$., et al. (2015). Effects of PTEN and nogo codeletion on corticospinal axon sprouting and regeneration in mice. J. Neurosci. 35, 6413-6428. doi: 10.1523/JNEUROSCI.4013-14.2015

Goldberg, J. L., Klassen, M. P., Hua, Y., and Barres, B. A. (2002). Amacrinesignaled loss of intrinsic axon growth ability by retinal ganglion cells. Science 296, 1860-1864. doi: 10.1126/science.1068428

Gray, S. J., Foti, S. B., Schwartz, J. W., Bachaboina, L., Taylor-Blake, B., Coleman, J., Ehlers, M. D., et al. (2011). Optimizing promoters for recombinant adenoassociated virus-mediated gene expression in the peripheral and central nervous system using self-complementary vectors. Hum. Gene Ther. 22, 1143-1153. doi: 10.1089/hum.2010.245

Groszer, M., Erickson, R., Scripture-Adams, D. D., Lesche, R., Trumpp, A., Zack, J. A., et al. (2001). Negative regulation of neural stem/progenitor cell proliferation by the Pten tumor suppressor gene in vivo. Science 294, 2186-2189. doi: 10.1126/science.1065518

Gu, H., Yu, S. P., Gutekunst, C.-A., Gross, R. E., and Wei, L. (2013). Inhibition of the Rho signaling pathway improves neurite outgrowth and neuronal differentiation of mouse neural stem cells. Int. J. Physiol. Pathophysiol. Pharmacol. 5, 11-20.

Guertin, D. A., and Sabatini, D. M. (2007). Defining the role of mTOR in cancer. Cancer Cell 12, 9-22. doi: 10.1016/j.ccr.2007.05.008

Gutilla, E. A., Buyukozturk, M. M., and Steward, O. (2016). Longterm consequences of conditional genetic deletion of PTEN in the sensorimotor cortex of neonatal mice. Exp. Neurol. 279, 27-39. doi: 10.1016/j.expneurol.2016.02.013

Hacein-Bey-Abina, S., Von Kalle, C., Schmidt, M., McCormack, M. P., Wulffraat, N., Leboulch, P., et al. (2003). LMO2-associated clonal T cell proliferation in two patients after gene therapy for SCID-X1. Science 302, 415-419. doi: 10.1126/science.1088547

Harel, N. Y., and Strittmatter, S. M. (2006). Can regenerating axons recapitulate developmental guidance during recovery from spinal cord injury? Nat. Rev. Neurosci. 7, 603-616. doi: 10.1038/nrn1957

Hargrave, M., Wright, E., Kun, J., Emery, J., Cooper, L., and Koopman, P. (1997). Expression of theSox11 gene in mouse embryos suggests roles in neuronal maturation and epithelio-mesenchymal induction. Dev. Dyn. 210, 79-86. doi: 10.1002/(SICI)1097-0177(199710)210:2\&lt;79::AID-AJA1\&gt;3.0.CO;2-6

Hastie, E., and Samulski, R. J. (2015). Adeno-associated virus at 50: a golden anniversary of discovery, research, and gene therapy success-a personal perspective. Hum. Gene Ther. 26, 257-265. doi: 10.1089/hum.2015.025

He, B., You, L., Uematsu, K., Zang, K., Xu, Z., Lee, A. Y., et al. (2003). SOCS3 is frequently silenced by hypermethylation and suppresses cell growth in human lung cancer. Proc. Natl. Acad. Sci. U.S.A. 100, 14133-14138. doi: 10.1073 /pnas. 2232790100

He, Z., and Jin, Y. (2016). Intrinsic control of axon regeneration. Neuron 90, 437-451. doi: 10.1016/j.neuron.2016.04.022

Hellström, M., Muhling, J., Ehlert, E. M., Verhaagen, J., Pollett, M. A., Hu, Y., et al. (2011). Negative impact of rAAV2 mediated expression of SOCS3 on the regeneration of adult retinal ganglion cell axons. Mol. Cell. Neurosci. 46, 507-515. doi: 10.1016/j.mcn.2010.12.003

Hollis, E. R., Lu, P., Blesch, A., and Tuszynski, M. H. (2009). IGF-I gene delivery promotes corticospinal neuronal survival but not regeneration after adult CNS injury. Exp. Neurol. 215, 53-59. doi: 10.1016/j.expneurol.2008.09.014

Hoshiba, Y., Toda, T., Ebisu, H., Wakimoto, M., Yanagi, S., and Kawasaki, H. (2016). Sox11 balances dendritic morphogenesis with neuronal migration in the developing cerebral cortex. J. Neurosci. 36, 5775-5784. doi: 10.1523/JNEUROSCI.3250-15.2016

Houlé, J. D., and Reier, P. J. (1988). Transplantation of fetal spinal cord tissue into the chronically injured adult rat spinal cord. J. Comp. Neurol. 269, 535-547. doi: $10.1002 /$ cne.902690406

Hsia, H.-E., Kumar, R., Luca, R., Takeda, M., Courchet, J., Nakashima, J., et al. (2014). Ubiquitin E3 ligase Nedd4-1 acts as a downstream target of PI3K/PTEN-mTORC1 signaling to promote neurite growth. Proc. Natl. Acad. Sci. U.S.A. 111, 13205-13210. doi: 10.1073/pnas.1400737111

Huebner, E. A., and Strittmatter, S. M. (2009). "Axon regeneration in the peripheral and central nervous systems," in Cell Biology of the Axon. Results and Problems in Cell Differentiation, Vol. 48, ed E. Koenig (Berlin; Heidelberg: Springer).

Hutson, T. H., Verhaagen, J., Yáñez-Muñoz, R. J., and Moon, L. D. F. (2012). Corticospinal tract transduction: a comparison of seven adeno-associated viral vector serotypes and a non-integrating lentiviral vector. Gene Ther. 19, 49-60. doi: 10.1038/gt.2011.71

Ishizaki, T., Naito, M., Fujisawa, K., Maekawa, M., Watanabe, N., Saito, Y., et al. (1997). p160ROCK, a Rho-associated coiled-coil forming protein kinase, works downstream of Rho and induces focal adhesions. FEBS Lett. 404, 118-124. doi: 10.1016/S0014-5793(97)00107-5

Jalink, K., van Corven, E. J., Hengeveld, T., Morii, N., Narumiya, S., and Moolenaar, W. H. (1994). Inhibition of lysophosphatidate- and thrombin-induced neurite retraction and neuronal cell rounding by $\mathrm{ADP}$ ribosylation of the small GTP-binding protein Rho. J. Cell Biol. 126, 801-810. doi: 10.1083/jcb.126. 3.801

Jin, D., Liu, Y., Sun, F., Wang, X., Liu, X., and He, Z. (2015). Restoration of skilled locomotion by sprouting corticospinal axons induced by co-deletion of PTEN and SOCS3. Nat. Commun. 6:8074. doi: 10.1038/ncomms9074

von Jonquieres, G., Mersmann, N., Klugmann, C. B., Harasta, A. E., Lutz, B. Teahan, O., et al. (2013). Glial promoter selectivity following AAV-delivery to the immature brain. PLoS ONE 8:e65646. doi: 10.1371/journal.pone.0065646

Jung, C. H., Jun, C. B., Ro, S.-H., Kim, Y.-M., Otto, N. M., Cao, J., et al. (2009). ULK-Atg13-FIP200 complexes mediate mTOR signaling to the autophagy machinery. Mol. Biol. Cell 20, 1992-2003. doi: 10.1091/mbc.E08-12-1249

Kalil, K., and Reh, T. (1979). Regrowth of severed axons in the neonatal central nervous system: establishment of normal connections. Science 205, 1158-1161. doi: 10.1126/science.472734

Kaplitt, M. G., Leone, P., Samulski, R. J., Xiao, X., Pfaff, D. W., O’Malley, K. L., et al. (1994). Long-term gene expression and phenotypic correction using adeno-associated virus vectors in the mammalian brain. Nat. Genet. 8, 148-154.

Klein, R. L., Meyer, E. M., Peel, A. L., Zolotukhin, S., Meyers, C., Muzyczka, N., et al. (1998). Neuron-specific transduction in the rat septohippocampal or nigrostriatal pathway by recombinant adeno-associated virus vectors. Exp. Neurol. 150, 183-194. doi: 10.1006/exnr.1997.6736

Koch, J. C., Tönges, L., Barski, E., Michel, U., Bähr, M., and Lingor, P. (2014a). ROCK2 is a major regulator of axonal degeneration, neuronal death and axonal regeneration in the CNS. Cell Death Dis. 5:e1225. doi: 10.1038/cddis.20 14.191

Koch, J. C., Tonges, L., Michel, U., Bahr, M., and Lingor, P. (2014b). Viral vector-mediated downregulation of RhoA increases survival and axonal regeneration of retinal ganglion cells. Front. Cell. Neurosci. 8:273. doi: 10.3389/fncel.2014.00273

Krebs, D. L., and Hilton, D. J. (2001). SOCS proteins: negative regulators of cytokine signaling. Stem Cells 19, 378-387. doi: 10.1634/stemcells.19-5-378

Kügler, S., Kilic, E., and Bähr, M. (2003). Human synapsin 1 gene promoter confers highly neuron-specific long-term transgene expression from an adenoviral vector in the adult rat brain depending on the transduced area. Gene Ther. 10, 337-347. doi: 10.1038/sj.gt.3301905

Kwon, C.-H., Luikart, B. W., Powell, C. M., Zhou, J., Matheny, S. A., Zhang, W. et al. (2006). Pten regulates neuronal arborization and social interaction in mice. Neuron 50, 377-388. doi: 10.1016/j.neuron.2006.03.023

Landeira, B. S., Santana, T. T., Araújo, J. A., Tabet, E. I., Tannous, B. A., Schroeder, T., et al. (2016). Activity-independent effects of CREB on neuronal survival and differentiation during mouse cerebral cortex development. Cereb. Cortex. doi: 10.1093/cercor/bhw387. [Epub ahead of print].

Lang, C., Bradley, P. M., Jacobi, A., Kerschensteiner, M., and Bareyre, F. M. (2013). STAT3 promotes corticospinal remodelling and functional recovery after spinal cord injury. EMBO Rep. 14, 931-937. doi: 10.1038/embor.2013.117 
LaSarge, C. L., Santos, V. R., and Danzer, S. C. (2015). PTEN deletion from adultgenerated dentate granule cells disrupts granule cell mossy fiber axon structure. Neurobiol. Dis. 75, 142-150. doi: 10.1016/j.nbd.2014.12.029

Lawlor, P. A., Bland, R. J., Mouravlev, A., Young, D., and During, M. J. (2009). Efficient gene delivery and selective transduction of glial cells in the mammalian brain by AAV serotypes isolated from nonhuman primates. Mol. Ther. 17, 1692-1702. doi: 10.1038/mt.2009.170

Lebherz, C., Maguire, A., Tang, W., Bennett, J., and Wilson, J. M. (2008). Novel AAV serotypes for improved ocular gene transfer. J. Gene Med. 10, 375-382. doi: $10.1002 /$ jgm. 1126

Lee, J. K., Geoffroy, C. G., Chan, A. F., Tolentino, K. E., Crawford, M. J., Leal, M. A., et al. (2010). Assessing spinal axon regeneration and sprouting in Nogo-, MAG-, and OMgp-deficient mice. Neuron 66, 663-670. doi: 10.1016/j.neuron.2010.05.002

Lehtinen, M. K., Zappaterra, M. W., Chen, X., Yang, Y. J., Hill, A. D., Lun, M., et al. (2011). The cerebrospinal fluid provides a proliferative niche for neural progenitor cells. Neuron 69, 893-905. doi: 10.1016/j.neuron.2011.01.023

Lemon, R. N., and Griffiths, J. (2005). Comparing the function of the corticospinal system in different species: organizational differences for motor specialization? Muscle Nerve 32, 261-279. doi: 10.1002/mus.20333

Lewandowski, G., and Steward, O. (2014). AAVshRNA-mediated suppression of PTEN in adult rats in combination with salmon fibrin administration enables regenerative growth of corticospinal axons and enhances recovery of voluntary motor function after cervical spinal cord injury. J. Neurosci. 34, 9951-9962. doi: 10.1523/JNEUROSCI.1996-14.2014

Li, Z., Düllmann, J., Schiedlmeier, B., Schmidt, M., von Kalle, C., Meyer, J., et al. (2002). Murine leukemia induced by retroviral gene marking. Science 296, 497-497. doi: 10.1126/science. 1068893

Liang, F.-Q., Dejneka, N. S., Cohen, D. R., Krasnoperova, N. V., Lem, J., Maguire, A. M., et al. (2001). AAV-mediated delivery of ciliary neurotrophic factor prolongs photoreceptor survival in the rhodopsin knockout mouse. Mol. Ther. 3, 241-248. doi: 10.1006/mthe.2000.0252

Lim, J.-H. A., Stafford, B. K., Nguyen, P. L., Lien, B. V., Wang, C., Zukor, K., et al. (2016). Neural activity promotes long-distance, target-specific regeneration of adult retinal axons. Nat. Neurosci. 19, 1073-1084. doi: 10.1038/nn.4340

Lim, S. T., Airavaara, M., and Harvey, B. K. (2010). Viral vectors for neurotrophic factor delivery: a gene therapy approach for neurodegenerative diseases of the CNS. Pharmacol. Res. 61, 14-26. doi: 10.1016/j.phrs.2009.10.002

Lin, L., Lee, V. M., Wang, Y., Lin, J. S., Sock, E., Wegner, M., et al. (2011). Sox11 regulates survival and axonal growth of embryonic sensory neurons. Dev. Dyn. 240, 52-64. doi: 10.1002/dvdy.22489

Lin, X., Ogiya, M., Takahara, M., Yamaguchi, W., Furuyama, T., Tanaka, H., et al. (2007). Sema4D-plexin-B1 implicated in regulation of dendritic spine density through RhoA/ROCK pathway. Neurosci. Lett. 428, 1-6. doi: 10.1016/j.neulet.2007.09.045

Lingor, P., Koeberle, P., Kügler, S., and Bähr, M. (2005). Down-regulation of apoptosis mediators by RNAi inhibits axotomy-induced retinal ganglion cell death in vivo. Brain 128, 550-558. doi: 10.1093/brain/awh382

Liu, K., Lu, Y., Lee, J. K., Samara, R., Willenberg, R., Sears-Kraxberger, I., et al. (2010). PTEN deletion enhances the regenerative ability of adult corticospinal neurons. Nat. Neurosci. 13, 1075-1081. doi: 10.1038/nn.2603

Liu, K., Tedeschi, A., Park, K. K., and He, Z. (2011). Neuronal intrinsic mechanisms of axon regeneration. Annu. Rev. Neurosci. 34, 131-152. doi: 10.1146/annurev-neuro-061010-113723

Liu, X., Williams, P. R., and He, Z. (2015). SOCS3: a common target for neuronal protection and axon regeneration after spinal cord injury. Exp. Neurol. 263, 364-367. doi: 10.1016/j.expneurol.2014.10.024

Luo, J., Manning, B. D., and Cantley, L. C. (2003). Targeting the PI3K-Akt pathway in human cancer: rationale and promise. Cancer Cell 4, 257-262. doi: 10.1016/S1535-6108(03)00248-4

Ma, X. M., and Blenis, J. (2009). Molecular mechanisms of mTORmediated translational control. Nat. Rev. Mol. Cell Biol. 10, 307-318. doi: $10.1038 / \mathrm{nrm} 2672$

Mandel, R. J., and Burger, C. (2004). Clinical trials in neurological disorders using AAV vectors: promises and challenges. Curr. Opin. Mol. Ther. 6, 482-490.

Mar, F. M., Bonni, A., and Sousa, M. M. (2014). Cell intrinsic control of axon regeneration. EMBO Rep. 15, 254-263. doi: 10.1002/embr.201337723
Masserdotti, G., Gillotin, S., Sutor, B., Drechsel, D., Irmler, M., Jørgensen, H. F., et al. (2015). Transcriptional mechanisms of proneural factors and REST in regulating neuronal reprogramming of astrocytes. Cell Stem Cell 17, 74-88. doi: $10.1016 /$ j.stem.2015.05.014

McCown, T. J. (2011). Adeno-associated virus (AAV) vectors in the CNS. Curr. Gene Ther. 11, 181-188. doi: 10.2174/156652311795684759

McLean, J. R., Smith, G. A., Rocha, E. M., Hayes, M. A., Beagan, J. A., Hallett, P. J., et al. (2014). Widespread neuron-specific transgene expression in brain and spinal cord following synapsin promoter-driven AAV9 neonatal intracerebroventricular injection. Neurosci. Lett. 576, 73-78. doi: 10.1016/j.neulet.2014.05.044

Mehta, S. T., Luo, X., Park, K. K., Bixby, J. L., and Lemmon, V. P. (2016). Hyperactivated Stat3 boosts axon regeneration in the CNS. Exp. Neurol. 280, 115-120. doi: 10.1016/j.expneurol.2016.03.004

Meyer, N., and Penn, L. Z. (2008). Reflecting on 25 years with MYC. Nat. Rev. Cancer 8, 976-990. doi: 10.1038/nrc2231

Miao, T., Wu, D., Zhang, Y., Bo, X., Subang, M. C., Wang, P., et al. (2006). Suppressor of cytokine signaling-3 suppresses the ability of activated signal transducer and activator of transcription-3 to stimulate neurite growth in rat primary sensory neurons. J. Neurosci. 26, 9512-9519. doi: 10.1523/JNEUROSCI.2160-06.2006

Miller, F. D., and Gauthier, A. S. (2007). Timing is everything: making neurons versus glia in the developing cortex. Neuron 54, 357-369. doi: 10.1016/j.neuron.2007.04.019

Mingozzi, F., and High, K. A. (2011). Therapeutic in vivo gene transfer for genetic disease using AAV: progress and challenges. Nat. Rev. Genet. 12, 341-355. doi: $10.1038 / \mathrm{nrg} 2988$

Montminy, M. R., and Bilezikjian, L. M. (1987). Binding of a nuclear protein to the cyclic-AMP response element of the somatostatin gene. Nature 328, 175-178. doi: $10.1038 / 328175 \mathrm{a} 0$

Moore, D. L., Blackmore, M. G., Hu, Y., Kaestner, K. H., Bixby, J. L., Lemmon, V. P., et al. (2009). KLF family members regulate intrinsic axon regeneration ability. Science 326, 298-301. doi: 10.1126/science.1175737

Moreau-Fauvarque, C., Kumanogoh, A., Camand, E., Jaillard, C., Barbin, G., Boquet, I., et al. (2003). The transmembrane semaphorin Sema4D/CD100, an inhibitor of axonal growth, is expressed on oligodendrocytes and upregulated after CNS lesion. J. Neurosci. 23, 9229-9239.

Morgan-Smith, M., Wu, Y., Zhu, X., Pringle, J., and Snider, W. D. (2014). GSK-3 signaling in developing cortical neurons is essential for radial migration and dendritic orientation. Elife 3:e02663. doi: 10.7554/eLife. 02663

Mueller, B. K., Mack, H., and Teusch, N. (2005). Rho kinase, a promising drug target for neurological disorders. Nat. Rev. Drug Discov. 4, 387-398. doi: $10.1038 / \operatorname{nrd} 1719$

Muralidharan, B., Khatri, Z., Maheshwari, U., Gupta, R., Roy, B., Pradhan, S. J., et al. (2017). LHX2 interacts with the NuRD complex and regulates cortical neuron subtype determinants Fezf2 and Sox11. J. Neurosci. 37, 194-203. doi: 10.1523/JNEUROSCI.2836-16.2016

Nathanson, J. L., Yanagawa, Y., Obata, K., and Callaway, E. M. (2009). Preferential labeling of inhibitory and excitatory cortical neurons by endogenous tropism of adeno-associated virus and lentivirus vectors. Neuroscience 161, 441-450. doi: 10.1016/j.neuroscience.2009.03.032

Norsworthy, M. W., Bei, F., Kawaguchi, R., Wang, Q., Tran, N. M., Li, Y., et al. (2017). Sox11 expression promotes regeneration of some retinal ganglion cell types but kills others. Neuron 94, 1112-1120.e4. doi: 10.1016/j.neuron.2017.05.035

Papale, A., Cerovic, M., and Brambilla, R. (2009). Viral vector approaches to modify gene expression in the brain. J. Neurosci. Methods 185, 1-14. doi: 10.1016/j.jneumeth.2009.08.013

Park, K. K., Liu, K., Hu, Y., Smith, P. D., Wang, C., Cai, B., et al. (2008). Promoting axon regeneration in the adult CNS by modulation of the PTEN/mTOR pathway. Science 322, 963-966. doi: 10.1126/science.11 61566

Paterna, J. C., Moccetti, T., Mura, A., Feldon, J., and Büeler, H. (2000). Influence of promoter and WHV post-transcriptional regulatory element on AAVmediated transgene expression in the rat brain. Gene Ther. 7, 1304-1311. doi: 10.1038/sj.gt.3301221 
Penzo-Méndez, A. I. (2010). Critical roles for SoxC transcription factors in development and cancer. Int. J. Biochem. Cell Biol. 42, 425-428. doi: 10.1016/j.biocel.2009.07.018

Pernet, V., Joly, S., Jordi, N., Dalkara, D., Guzik-Kornacka, A., Flannery, J. G., et al. (2013). Misguidance and modulation of axonal regeneration by Stat 3 and Rho/ROCK signaling in the transparent optic nerve. Cell Death Dis. 4:e734. doi: 10.1038/cddis.2013.266

Ponder, K. P. (2000). "Vectors in gene therapy," in An Introduction to Molecular Medicine and Gene Therapy, ed T. F. Kresina (New York, NY: Wiley-Liss).

Qin, S., Zou, Y., and Zhang, C.-L. (2013). Cross-talk between KLF4 and STAT3 regulates axon regeneration. Nat. Commun. 4:2633. doi: 10.1038/ncom ms 3633

Rabinowitz, J. E., Rolling, F., Li, C., Conrath, H., Xiao, W., Xiao, X., et al. (2002). Cross-packaging of a single adeno-associated virus (AAV) type 2 vector genome into multiple AAV serotypes enables transduction with broad specificity. J. Virol. 76, 791-801. doi: 10.1128/JVI.76.2.791-801.2002

Raivich, G., Bohatschek, M., Da Costa, C., Iwata, O., Galiano, M., Hristova, M., et al. (2004). The AP-1 transcription factor c-Jun is required for efficient axonal regeneration. Neuron 43, 57-67. doi: 10.1016/j.neuron.2004.06.005

Ramon y Cajal, S. (1928). Degeneration and Regeneration of the Nervous System. Translated by R. M. May. London: Oxford University Press.

Raposo, A. A., Vasconcelos, F. F., Drechsel, D., Marie, C., Johnston, C., Dolle, D., et al. (2015). Ascll coordinately regulates gene expression and the chromatin landscape during neurogenesis. Cell Rep. 10, 1544-1556. doi: 10.1016/j.celrep.2015.02.025

Ribas, V. T., Koch, J. C., Michel, U., Bähr, M., and Lingor, P. (2017). Attenuation of axonal degeneration by calcium channel inhibitors improves retinal ganglion cell survival and regeneration after optic nerve crush. Mol. Neurobiol. 54, 72-86. doi: 10.1007/s12035-015-9676-2

Richardson, P. M., McGuinness, U. M., and Aguayo, A. J. (1980). Axons from CNS neurons regenerate into PNS grafts. Nature 284, 264-265. doi: $10.1038 / 284264 \mathrm{a} 0$

Saijilafu, Hur, E.-M., and Zhou, F.-Q. (2011). Genetic dissection of axon regeneration via in vivo electroporation of adult mouse sensory neurons. Nat. Commun. 2, 543. doi: 10.1038/ncomms1568

Sauer, B. (1998). Inducible gene targeting in mice using the Cre/loxsystem. Methods 14, 381-392. doi: 10.1006/meth.1998.0593

Saxton, R. A., and Sabatini, D. M. (2017). mTOR signaling in growth, metabolism, and disease. Cell 168, 960-976. doi: 10.1016/j.cell.2017.03.035

Schröder, A. R. W., Shinn, P., Chen, H., Berry, C., Ecker, J. R., and Bushman, F, (2002). HIV-1 integration in the human genome favors active genes and local hotspots. Cell 110, 521-529. doi: 10.1016/S0092-8674(02)00864-4

Schwab, M. E., and Bartholdi, D. (1996). Degeneration and regeneration of axons in the lesioned spinal cord. Physiol. Rev. 76, 319-370.

Schwab, M. E., and Strittmatter, S. M. (2014). Nogo limits neural plasticity and recovery from injury. Curr. Opin. Neurobiol. 27, 53-60. doi: 10.1016/j.conb.2014.02.011

Segura, M. M., Mangion, M., Gaillet, B., and Garnier, A. (2013). New developments in lentiviral vector design, production and purification. Expert Opin. Biol. Ther. 13, 987-1011. doi: 10.1517/14712598.2013.779249

Seijffers, R., Mills, C. D., and Woolf, C. J. (2007). ATF3 increases the intrinsic growth state of DRG neurons to enhance peripheral nerve regeneration. J. Neurosci. 27, 7911-7920. doi: 10.1523/JNEUROSCI.5313-06.2007

Shamah, S. M., Lin, M. Z., Goldberg, J. L., Estrach, S., Sahin, M., Hu, L., et al. (2001). EphA receptors regulate growth cone dynamics through the novel guanine nucleotide exchange factor ephexin. Cell 105, 233-244. doi: 10.1016/S0092-8674(01)00314-2

Shim, S., Kwan, K. Y., Li, M., Lefebvre, V., and Sestan, N. (2012). Cis-regulatory control of corticospinal system development and evolution. Nature 486, 74-79. doi: $10.1038 /$ nature1 1094

Silver, J., Schwab, M. E., and Popovich, P. G. (2015). Central nervous system regenerative failure: role of oligodendrocytes, astrocytes, and microglia. Cold Spring Harb. Perspect. Biol. 7:a020602. doi: 10.1101/cshperspect.a020602

Simonelli, F., Maguire, A. M., Testa, F., Pierce, E. A., Mingozzi, F., Bennicelli, J. L., et al. (2010). Gene therapy for leber's congenital amaurosis is safe and effective through 1.5 years after vector administration. Mol. Ther. 18, 643-650. doi: $10.1038 / \mathrm{mt} .2009 .277$
Smith, P. D., Sun, F., Park, K. K., Cai, B., Wang, C., Kuwako, K., et al. (2009). SOCS3 deletion promotes optic nerve regeneration in vivo. Neuron 64 , 617-623. doi: 10.1016/j.neuron.2009.11.021

Steward, O., Zheng, B., Ho, C., Anderson, K., and Tessier-Lavigne, M. (2004). The dorsolateral corticospinal tract in mice: an alternative route for corticospinal input to caudal segments following dorsal column lesions. J. Comp. Neurol. 472, 463-477. doi: 10.1002/cne.20090

Streilein, J. W. (2003). Ocular immune privilege: the eye takes a dim but practical view of immunity and inflammation. J. Leukoc. Biol. 74, 179-185. doi: $10.1189 / \mathrm{jlb} .1102574$

Sun, F., Park, K. K., Belin, S., Wang, D., Lu, T., Chen, G., et al. (2011). Sustained axon regeneration induced by co-deletion of PTEN and SOCS3. Nature 480, 372-375. doi: 10.1038/nature10594

Tanabe, K., Bonilla, I., Winkles, J. A., and Strittmatter, S. M. (2003). Fibroblast growth factor-inducible-14 is induced in axotomized neurons and promotes neurite outgrowth. J. Neurosci. 23, 9675-9686.

Testa, F., Maguire, A. M., Rossi, S., Pierce, E. A., Melillo, P., Marshall, K., et al. (2013). Three-year follow-up after unilateral subretinal delivery of adeno-associated virus in patients with Leber congenital Amaurosis type 2. Ophthalmology 120, 1283-1291. doi: 10.1016/j.ophtha.2012.11.048

Themis, M., Waddington, S. N., Schmidt, M., von Kalle, C., Wang, Y., Al-Allaf, F., et al. (2005). Oncogenesis following delivery of a nonprimate lentiviral gene therapy vector to fetal and neonatal mice. Mol. Ther. 12, 763-771. doi: $10.1016 /$ j.ymthe.2005.07.358

Tokita, T., Maesawa, C., Kimura, T., Kotani, K., Takahashi, K., Akasaka, T., et al. (2007). Methylation status of the SOCS3 gene in human malignant melanomas. Int. J. Oncol. 30, 689-694. doi: 10.3892/ijo.30.3.689

Vandenberghe, L. H., Wilson, J. M., and Gao, G. (2009). Tailoring the AAV vector capsid for gene therapy. Gene Ther. 16, 311-319. doi: 10.1038/gt.2008.170

Vasconcelos, F. F., and Castro, D. S. (2014). Transcriptional control of vertebrate neurogenesis by the proneural factor Ascl1. Front. Cell. Neurosci. 8:412. doi: $10.3389 /$ fncel.2014.00412

Vogt, V. M., and Simon, M. N. (1999). Mass determination of rous sarcoma virus virions by scanning transmission electron microscopy. J. Virol. 73, 7050-7055.

Wahl, S., Barth, H., Ciossek, T., Aktories, K., and Mueller, B. K. (2000). Ephrin-A5 induces collapse of growth cones by activating Rho and Rho kinase. J. Cell Biol. 149, 263-270. doi: 10.1083/jcb.149.2.263

Wang, J., Galvao, J., Beach, K. M., Luo, W., Urrutia, R. A., Goldberg, J. L., et al. (2016). Novel roles and mechanism for krüppel-like factor 16 (KLF16) regulation of neurite outgrowth and ephrin receptor A5 (EphA5) expression in retinal ganglion cells. J. Biol. Chem. 291, 18084-18095. doi: $10.1074 /$ jbc.A116.732339

Wang, Z., Reynolds, A., Kirry, A., Nienhaus, C., and Blackmore, M. G. (2015). Overexpression of Sox 11 promotes corticospinal tract regeneration after spinal injury while interfering with functional recovery. J. Neurosci. 35, 3139-3145. doi: 10.1523/JNEUROSCI.2832-14.2015

Watakabe, A., Ohtsuka, M., Kinoshita, M., Takaji, M., Isa, K., Mizukami, H., et al. (2015). Comparative analyses of adeno-associated viral vector serotypes 1, 2, 5, 8 and 9 in marmoset, mouse and macaque cerebral cortex. Neurosci. Res. 93, 144-157. doi: 10.1016/j.neures.2014.09.002

Watakabe, A., Sadakane, O., Hata, K., Ohtsuka, M., Takaji, M., and Yamamori, T. (2017). Application of viral vectors to the study of neural connectivities and neural circuits in the marmoset brain. Dev. Neurobiol. 77, 354-372. doi: 10.1002/dneu.22459

Williams, R. R., Venkatesh, I., Pearse, D. D., Udvadia, A. J., and Bunge, M. B. (2015). MASH1/Ascl1a leads to GAP43 expression and axon regeneration in the adult CNS. PLoS ONE 10:e0118918. doi: 10.1371/journal.pone.0118918

Wu, D., Yang, P., Zhang, X., Luo, J., Haque, M. E., Yeh, J., et al. (2009). Targeting a dominant negative rho kinase to neurons promotes axonal outgrowth and partial functional recovery after rat rubrospinal tract lesion. Mol. Ther. 17, 2020-2030. doi: $10.1038 / \mathrm{mt} .2009 .168$

Wu, Z., Asokan, A., and Samulski, R. J. (2006). Adeno-associated virus serotypes: vector toolkit for human gene therapy. Mol. Ther. 14, 316-327. doi: 10.1016/j.ymthe.2006.05.009

Wyatt, L. A., Filbin, M. T., and Keirstead, H. S. (2014). PTEN inhibition enhances neurite outgrowth in human embryonic stem cell-derived neuronal progenitor cells. J. Comp. Neurol. 522, 2741-2755. doi: 10.1002/cne.23580 
Yip, P. K., and Malaspina, A. (2012). Spinal cord trauma and the molecular point of no return. Mol. Neurodegener. 7:6. doi: 10.1186/1750-13 26-7-6

Yiu, G., and He, Z. (2006). Glial inhibition of CNS axon regeneration. Nat. Rev. Neurosci. 7, 617-627. doi: 10.1038/nrn1956

Yoshida, K., Behrens, A., Le-Niculescu, H., Wagner, E. F., Harada, T., Imaki, J., et al. (2002). Amino-terminal phosphorylation of c-Jun regulates apoptosis in the retinal ganglion cells by optic nerve transection. Invest. Ophthalmol. Vis. Sci. $43,1631-1635$

Young, P., Qiu, L., Wang, D., Zhao, S., Gross, J., and Feng, G. (2008). Singleneuron labeling with inducible Cre-mediated knockout in transgenic mice. Nat. Neurosci. 11, 721-728. doi: 10.1038/nn.2118

Zheng, B., Ho, C., Li, S., Keirstead, H., Steward, O., and Tessier-Lavigne, M. (2003). Lack of enhanced spinal regeneration in Nogo-deficient mice. Neuron 38, 213-224. doi: 10.1016/S0896-6273(03)00225-3
Zukor, K., Belin, S., Wang, C., Keelan, N., Wang, X., and He, Z. (2013). Short hairpin RNA against PTEN enhances regenerative growth of corticospinal tract axons after spinal cord injury. J. Neurosci. 33, 15350-15361. doi: 10.1523/JNEUROSCI.2510-13.2013

Conflict of Interest Statement: The authors declare that the research was conducted in the absence of any commercial or financial relationships that could be construed as a potential conflict of interest.

Copyright (ㅇ 2017 Ribas and Costa. This is an open-access article distributed under the terms of the Creative Commons Attribution License (CC BY). The use, distribution or reproduction in other forums is permitted, provided the original author(s) or licensor are credited and that the original publication in this journal is cited, in accordance with accepted academic practice. No use, distribution or reproduction is permitted which does not comply with these terms. 